\title{
Carbocatalytic acetylene cyclotrimerization: a key role of unpaired electron delocalization
}

\author{
Evgeniy G. Gordeev, Evgeniy O. Pentsak, Valentine P. Ananikov* \\ Zelinsky Institute of Organic Chemistry, Russian Academy of Sciences, \\ Leninsky prospekt 47, Moscow, 119991, Russia \\ val@ioc.ac.ru.
}

\section{Content:}

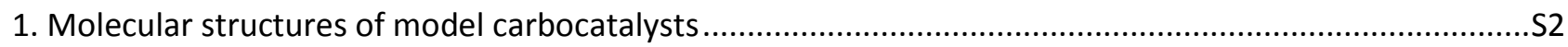

2. Acetylene trimerization with $\mathrm{C}_{37} \mathrm{H}_{14}$ carbene as a carbocatalyst..........................................................

3. Acetylene trimerization with $\mathrm{C}_{14} \mathrm{H}_{10}$ carbene as a carbocatalyst....................................................... 10

4. Acetylene trimerization with $\mathrm{C}_{37} \mathrm{H}_{15}$ and $\mathrm{C}_{19} \mathrm{H}_{11}$ (olympicenyl) monoradical carbocatalysts....................S17

5. Acetylene trimerization with non-Kekulé $\mathrm{C}_{25} \mathrm{H}_{12}$ carbocatalyst ......................................................S20

6. Acetylene trimerization with phenyl monoradical as a carbocatalyst ..................................................S23

7. Evaluation of the theoretical calculations accuracy for different basis sets and theory levels .................S27

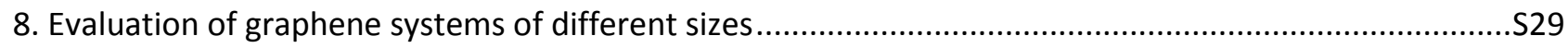

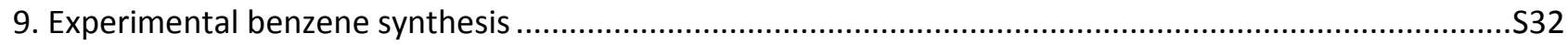




\section{Molecular structures of model carbocatalysts}

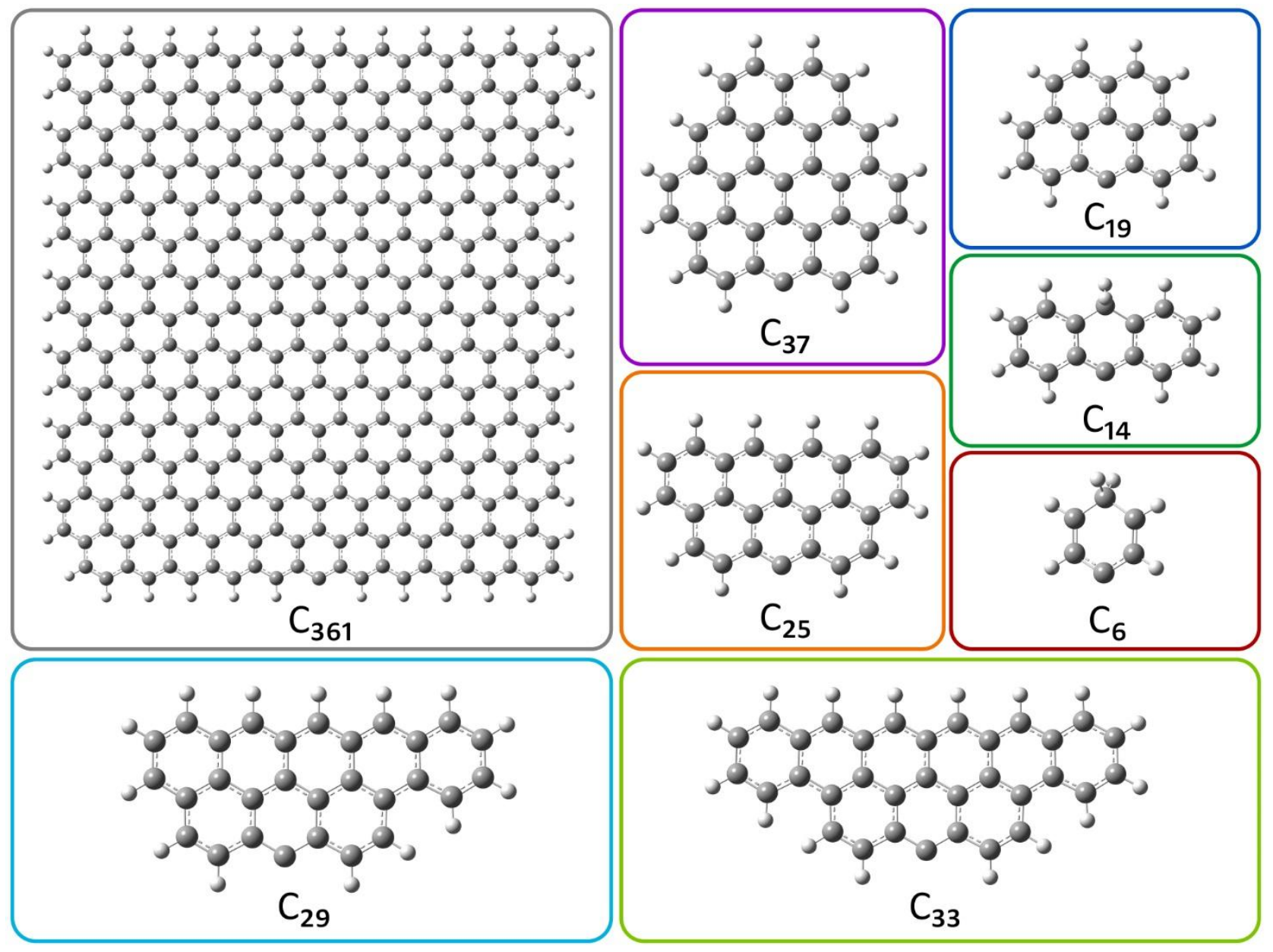

Figure S1. Molecular structures of model carbocatalysts used in the study: $\mathrm{C}_{361}, \mathrm{C}_{37}, \mathrm{C}_{33}, \mathrm{C}_{29}$, $\mathrm{C}_{25}, \mathrm{C}_{19}, \mathrm{C}_{14}$ and $\mathrm{C}_{6}$. 


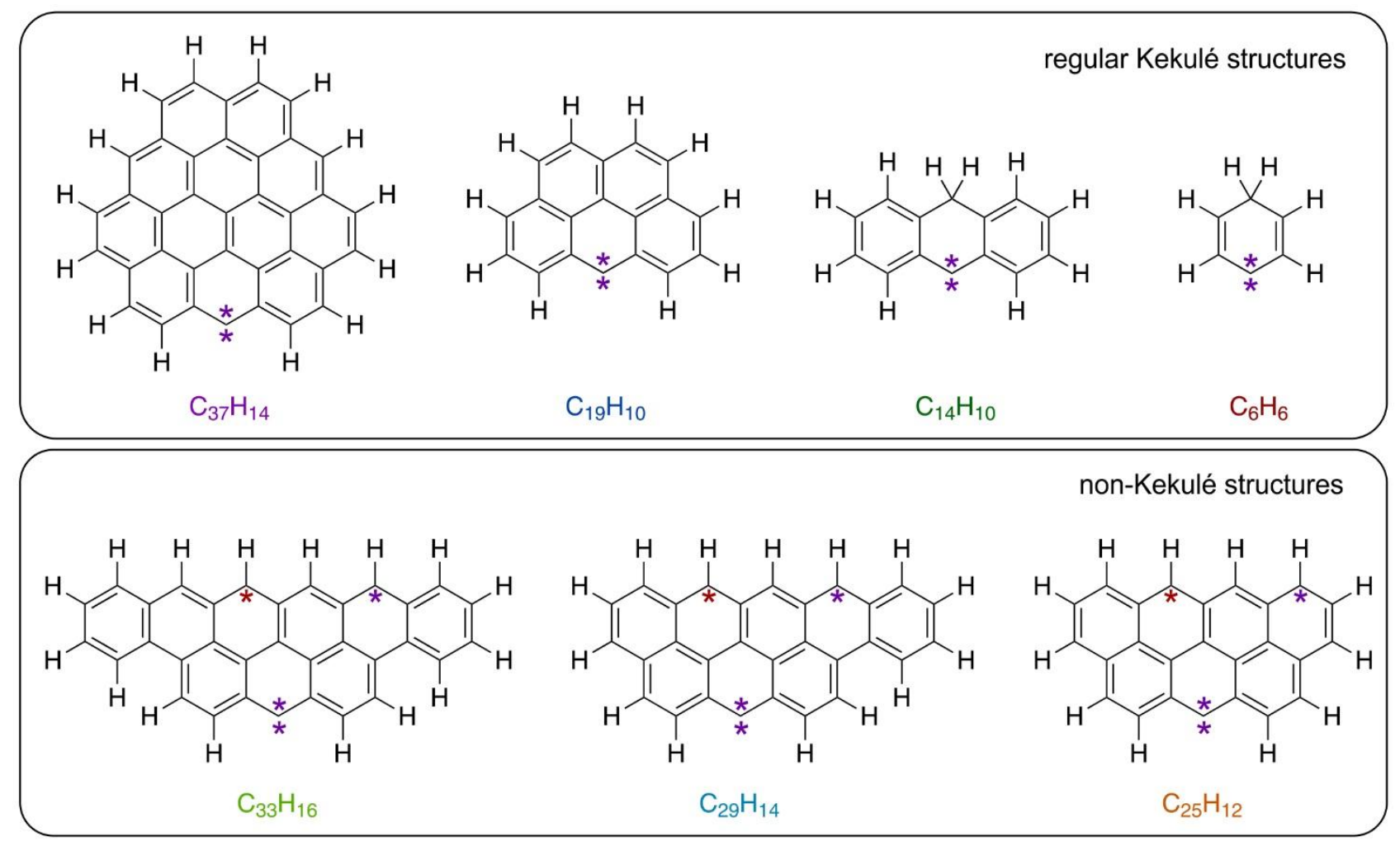

Figure S2. Regular Kekulé structures $\left(\mathrm{C}_{37} \mathrm{H}_{14}, \mathrm{C}_{19} \mathrm{H}_{10}, \mathrm{C}_{14} \mathrm{H}_{10}, \mathrm{C}_{6} \mathrm{H}_{6}\right)$ and non-Kekulé structures $\left(\mathrm{C}_{33} \mathrm{H}_{16}, \mathrm{C}_{29} \mathrm{H}_{14}, \mathrm{C}_{25} \mathrm{H}_{12}\right.$ with one of the possible allocations of unpaired electrons) of graphene flakes. Unpaired electrons are denoted by asterisks. 


\section{Acetylene trimerization with $\mathrm{C}_{37} \mathrm{H}_{14}$ carbene as a carbocatalyst}

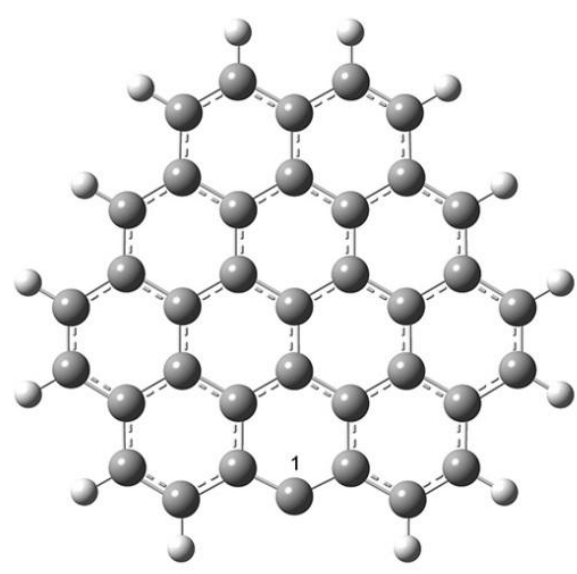

1
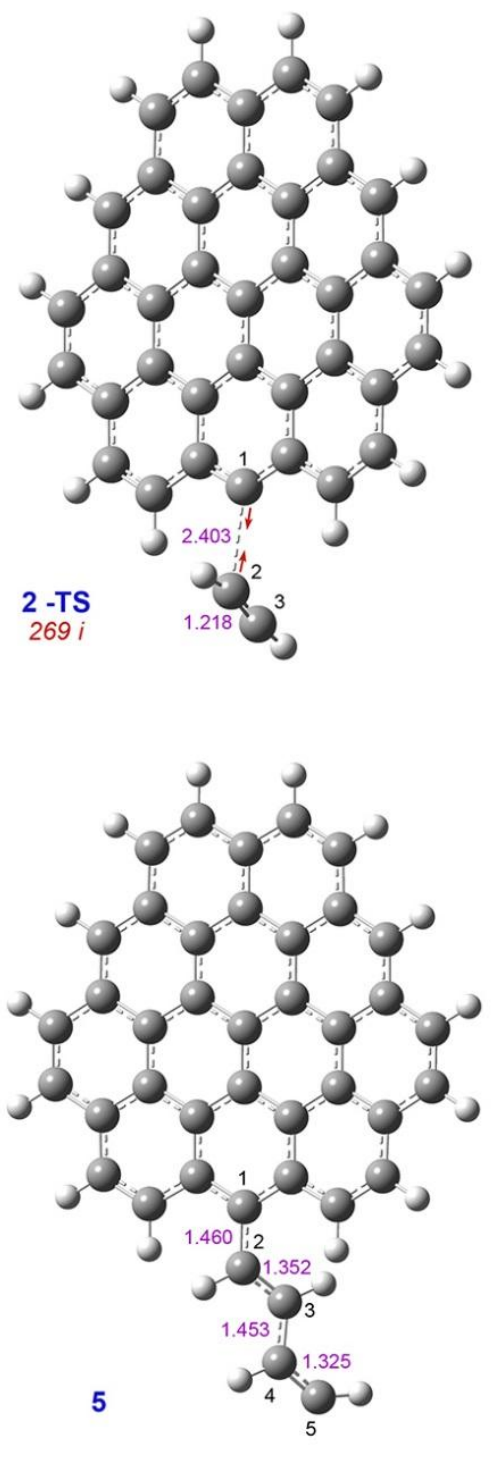
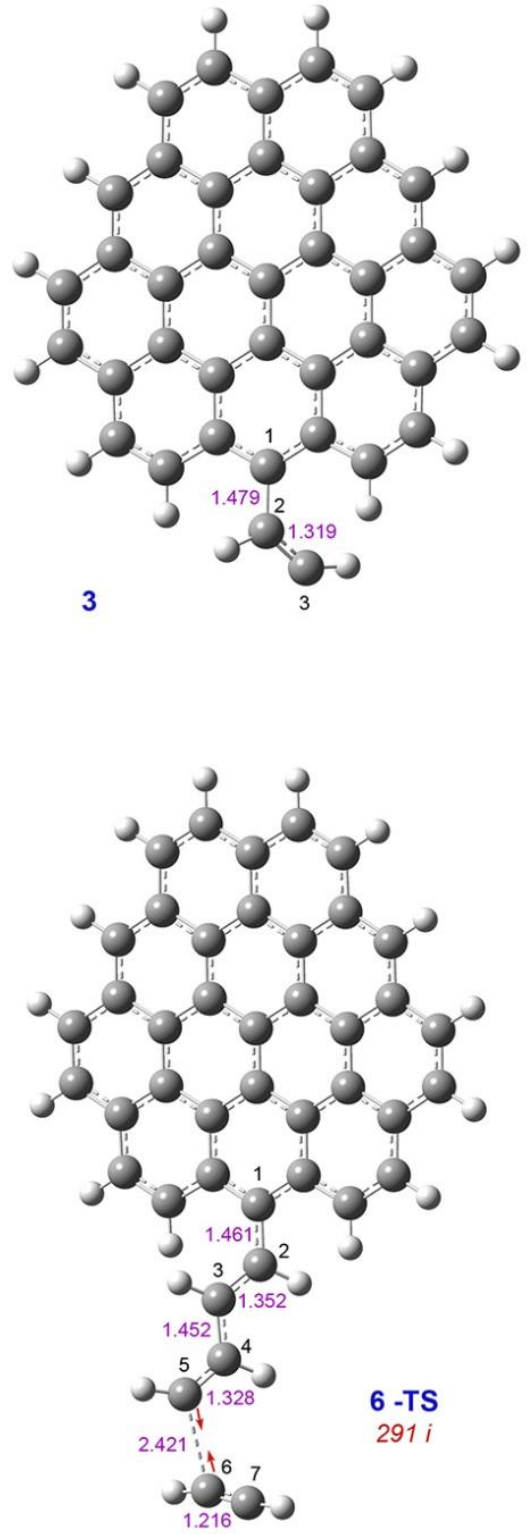

Figure S3. Optimized molecular structures of the stationary points $\mathbf{1}$ to 6-TS for the polycyclic triplet carbene-catalyzed reaction. The interatomic distances are displayed in angstroms. For each transition state, the imaginary frequency is shown; directions of atomic movements corresponding to imaginary frequencies are shown by red arrows; UPBE1PBE/6-31G(d) level. 

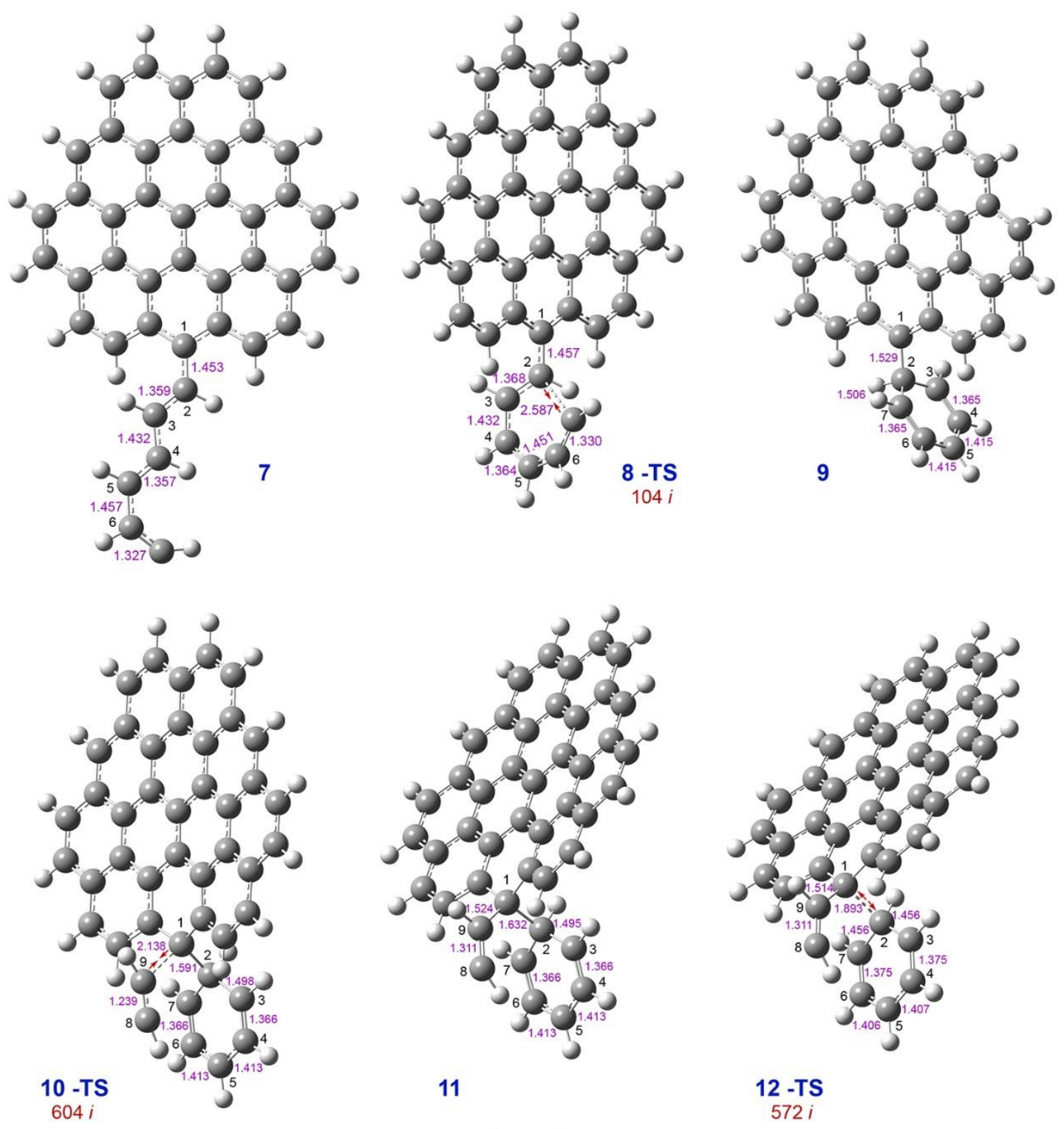

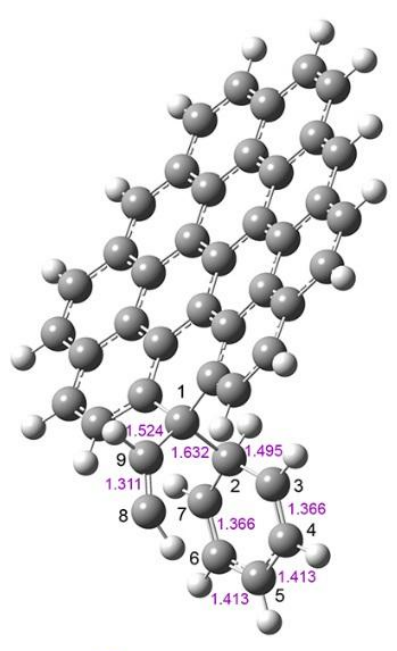

11

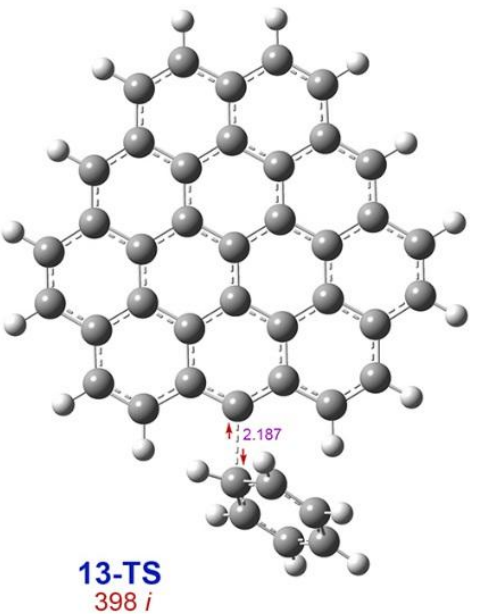

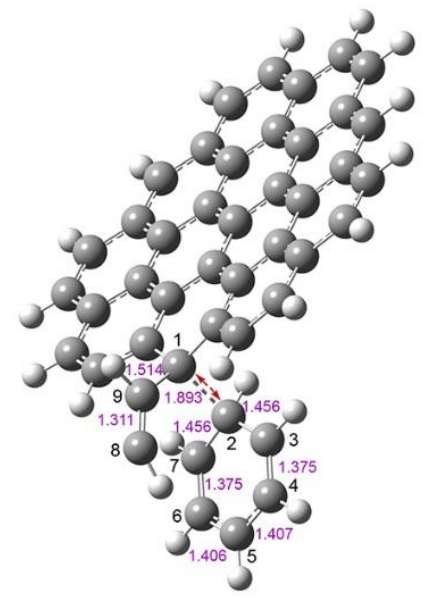

12 -TS

$572 i$

Figure S4. Optimized molecular structures of the stationary points 7 to 13-TS for the polycyclic triplet carbene-catalyzed reaction. The interatomic distances are displayed in angstroms. For each transition state, the imaginary frequency is shown; directions of atomic movements corresponding to imaginary frequencies are shown by red arrows; UPBE1PBE/6-31G(d) level. 


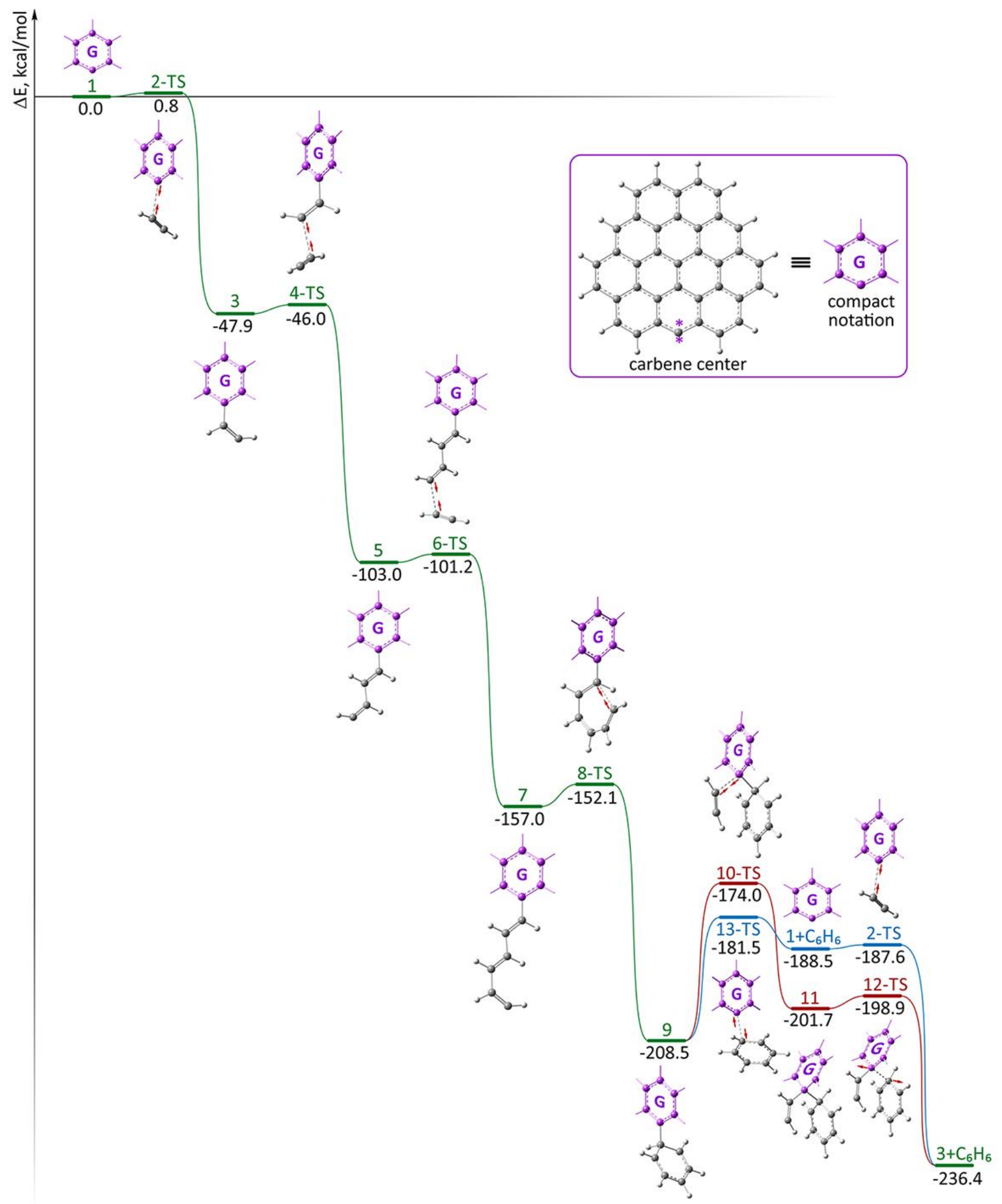

Figure S5. Total energy profile of acetylene cyclotrimerization reaction $(\Delta \mathrm{E})$ with $\mathrm{C}_{37} \mathrm{H}_{14}$ carbene as a catalyst; UPBE1PBE/6-31G(d) level. 


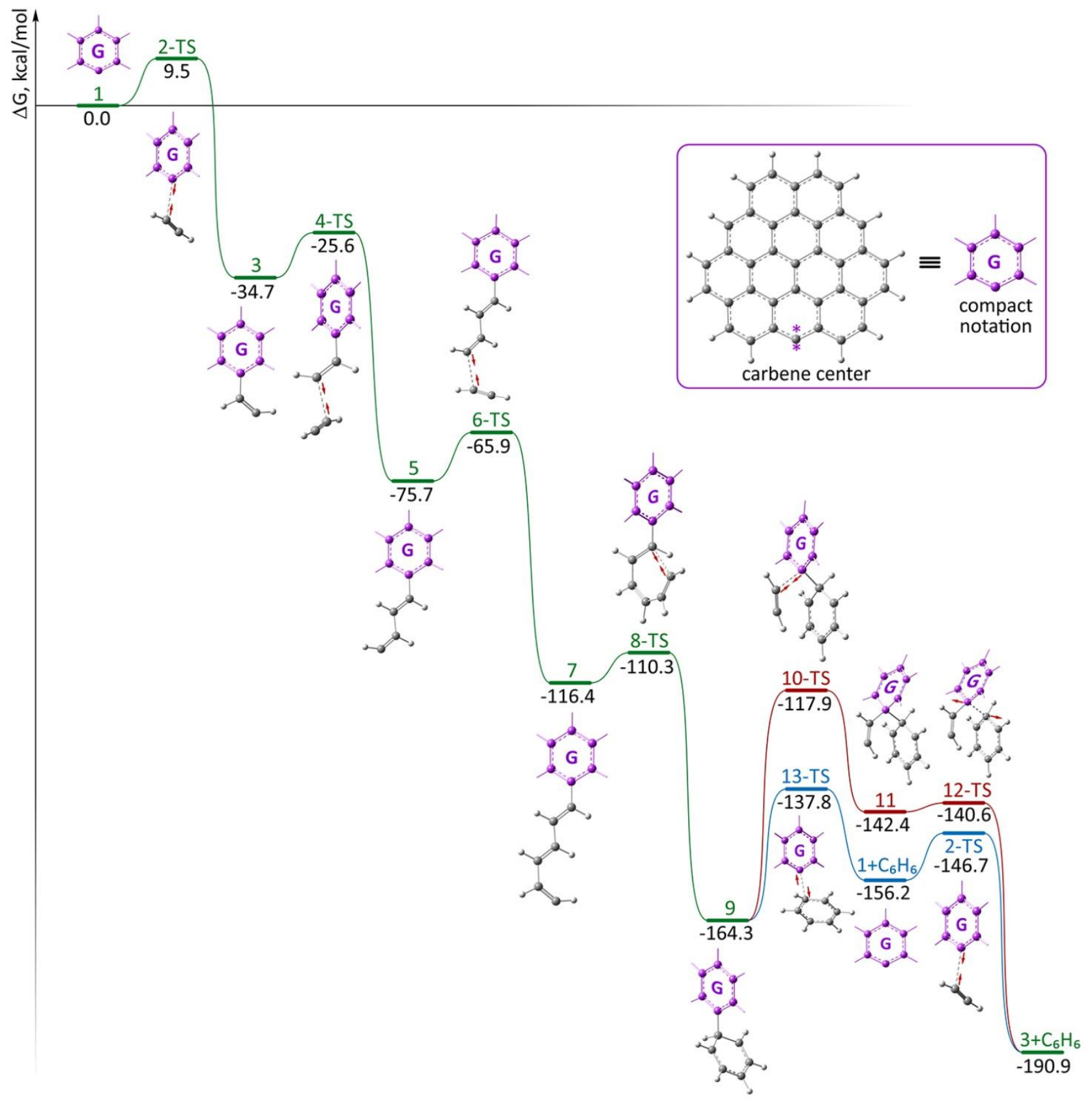

Figure S6. Free energy profile of acetylene cyclotrimerization reaction $(\Delta \mathrm{G})$ with $\mathrm{C}_{37} \mathrm{H}_{14}$ carbene as a catalyst; UPBE1PBE/6-31G(d) level. 


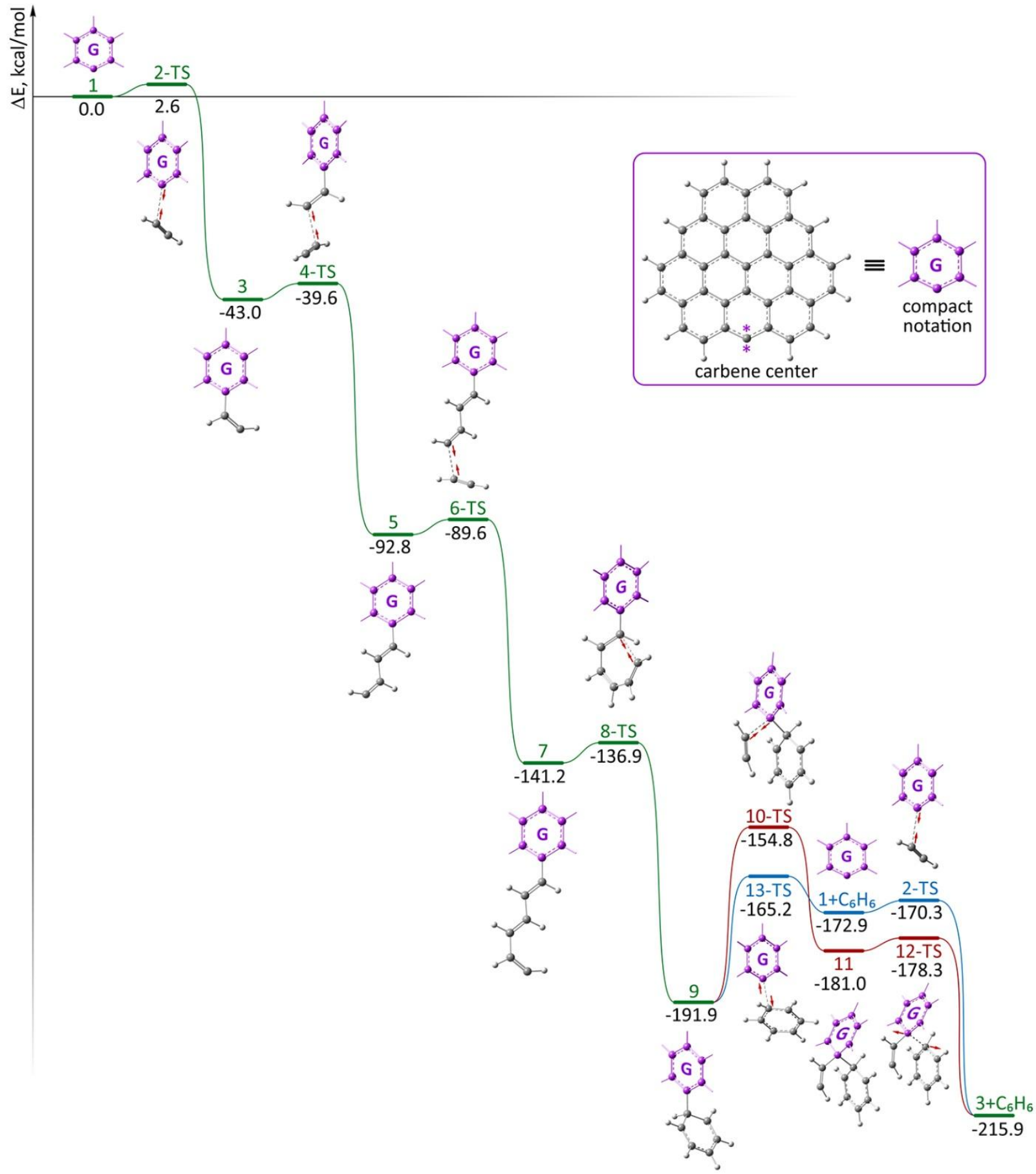

Figure S7. Total energy profile of acetylene cyclotrimerization reaction $(\Delta \mathrm{E})$ with $\mathrm{C}_{37} \mathrm{H}_{14}$ carbene as a catalyst; single point calculations at UPBE1PBE/6-311++G(d,p) level for geometries optimized at UPBE1PBE/6-31G(d) level. 


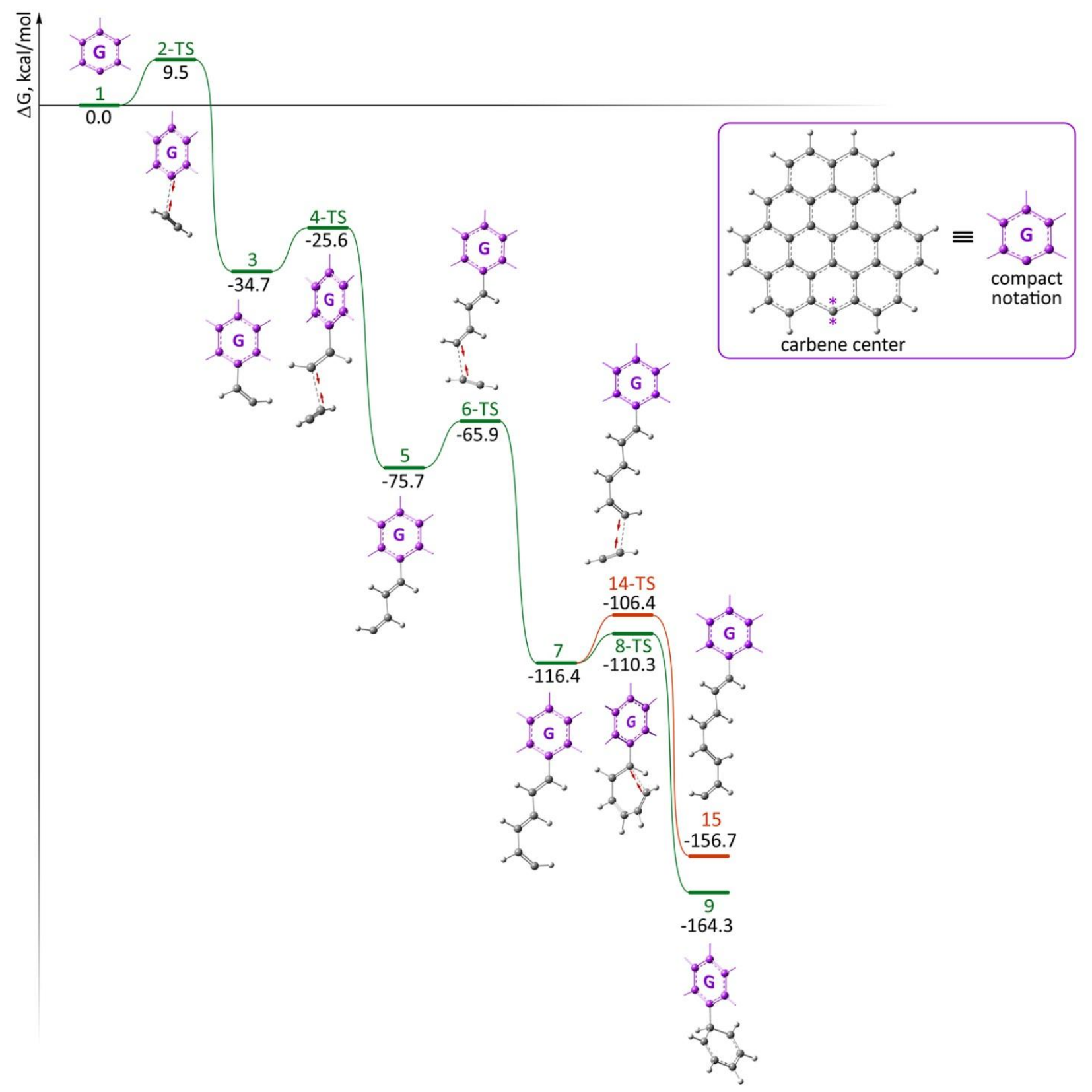

Figure S8. Free energy profiles of acetylene cyclotrimerization (green line) and linear tetramerization (orange line) reactions with $\mathrm{C}_{37} \mathrm{H}_{14}$ carbene as a catalyst; UPBE1PBE/6-31G(d) level. 


\section{Acetylene trimerization with $\mathrm{C}_{14} \mathrm{H}_{10}$ carbene as a carbocatalyst}

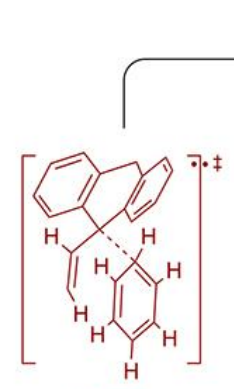

12-TS

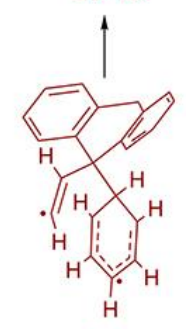

11

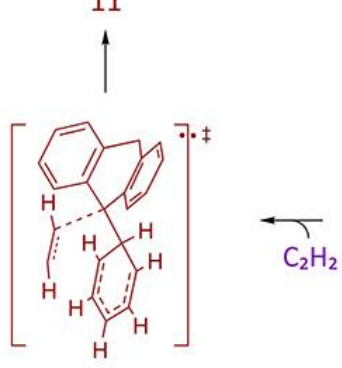

10-TS
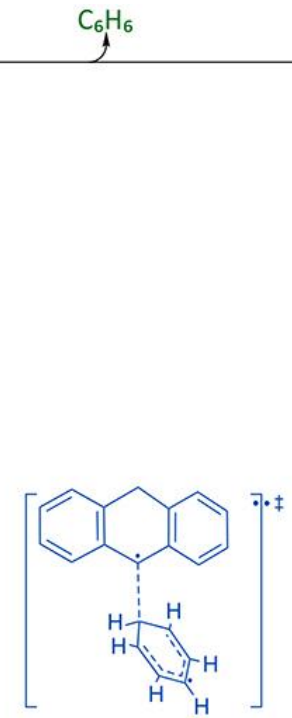

13-TS

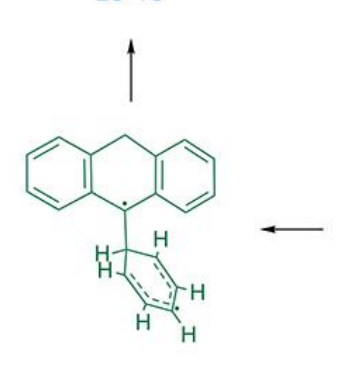

9

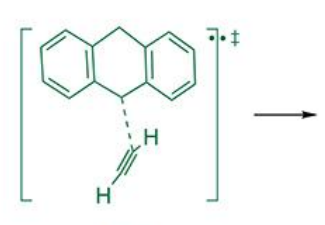

2-TS
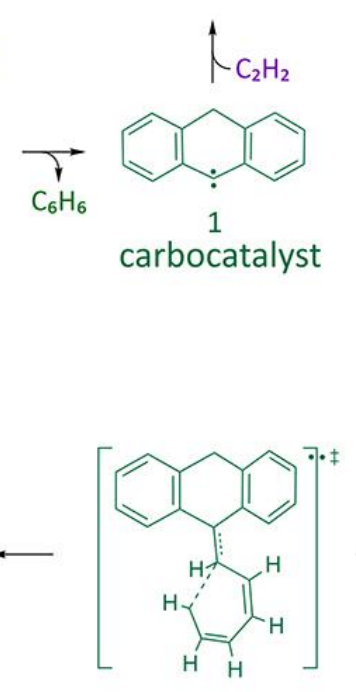

8-TS

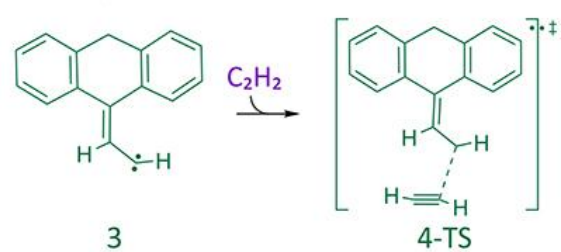

3
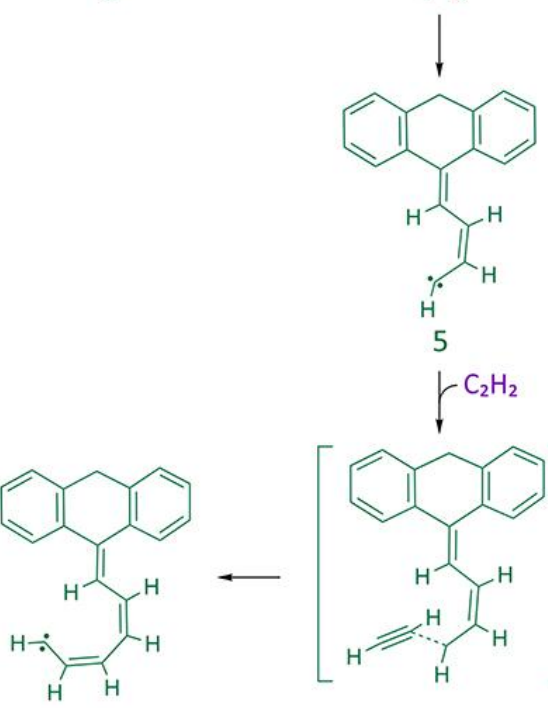

7

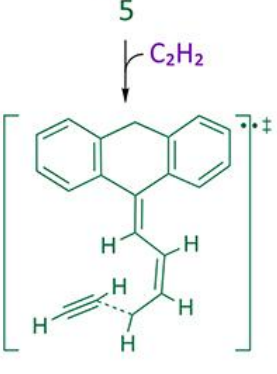

6-TS

Figure S9. Acetylene cyclotrimerization reaction with tricyclic $\mathrm{C}_{14} \mathrm{H}_{10}$ carbene as a catalyst. 


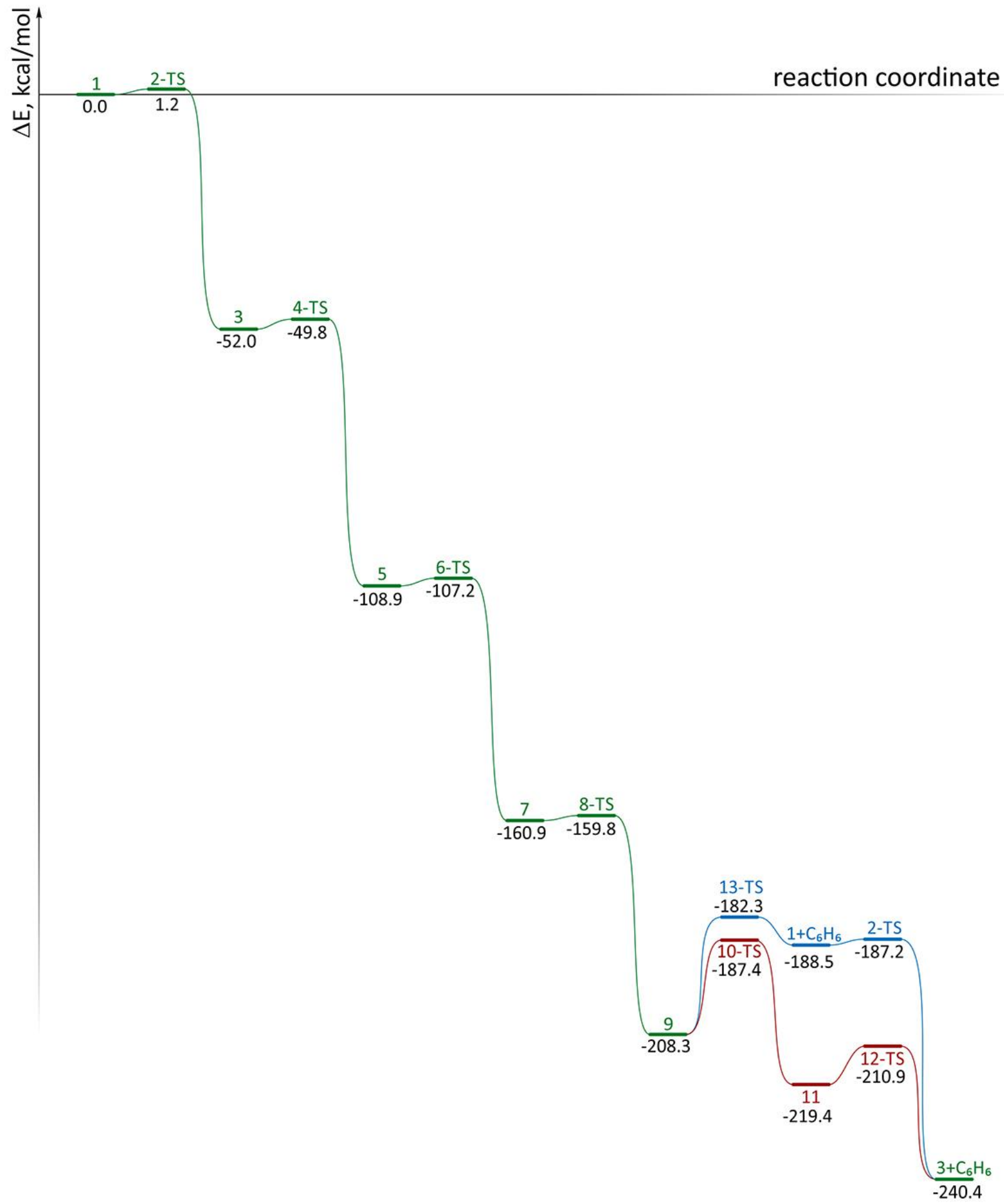

Figure S10. Total energy profile $(\Delta \mathrm{E})$ of acetylene cyclotrimerization reaction with $\mathrm{C}_{14} \mathrm{H}_{10}$ tricyclic carbene as a catalyst; UPBE1PBE/6-31G(d) level. 


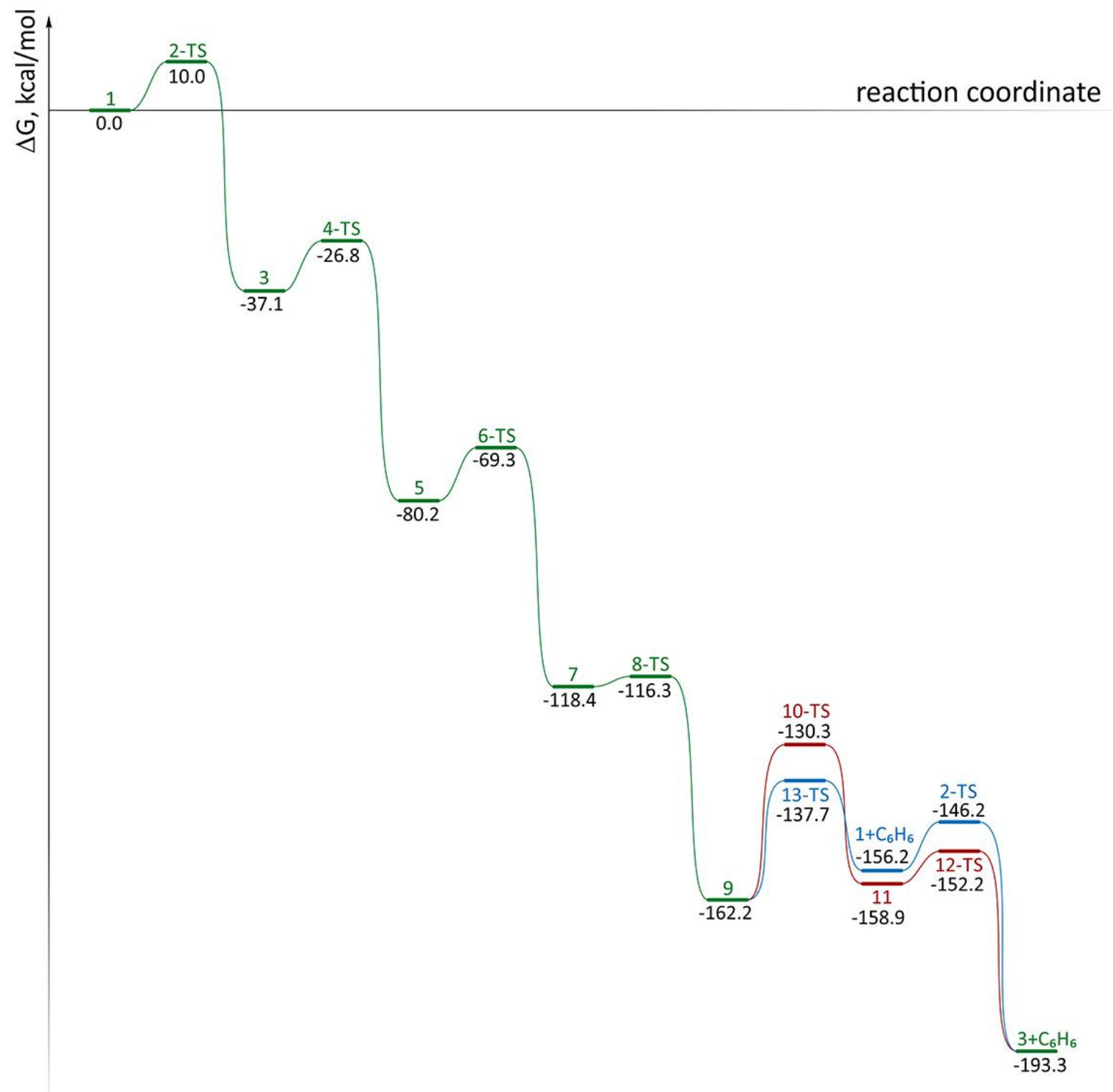

Figure S11. Gibbs free energy profile $(\Delta \mathrm{G})$ of acetylene cyclotrimerization reaction with $\mathrm{C}_{14} \mathrm{H}_{10}$ tricyclic carbene as a catalyst; UPBE1PBE/6-31G(d) level. 

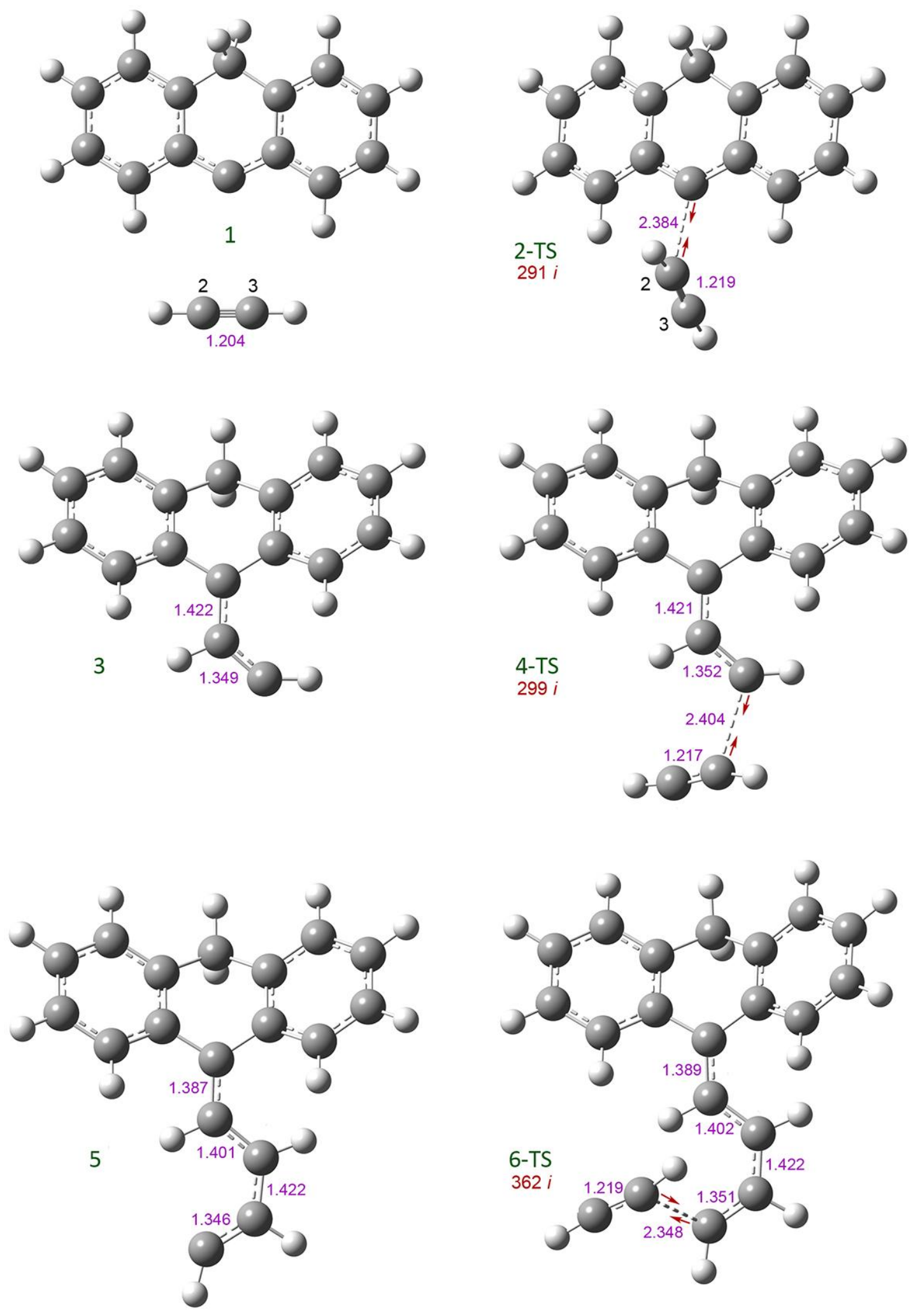

Figure S12. Optimized molecular structures of the stationary points $\mathbf{1}-\mathbf{6}$-TS for the tricyclic triplet carbene-catalyzed reaction. The interatomic distances are in angstroms. For each transition state, the imaginary frequency is shown; directions of atomic movements corresponding to imaginary frequencies are shown by red arrows; UPBE1PBE/6-31G(d) level. 

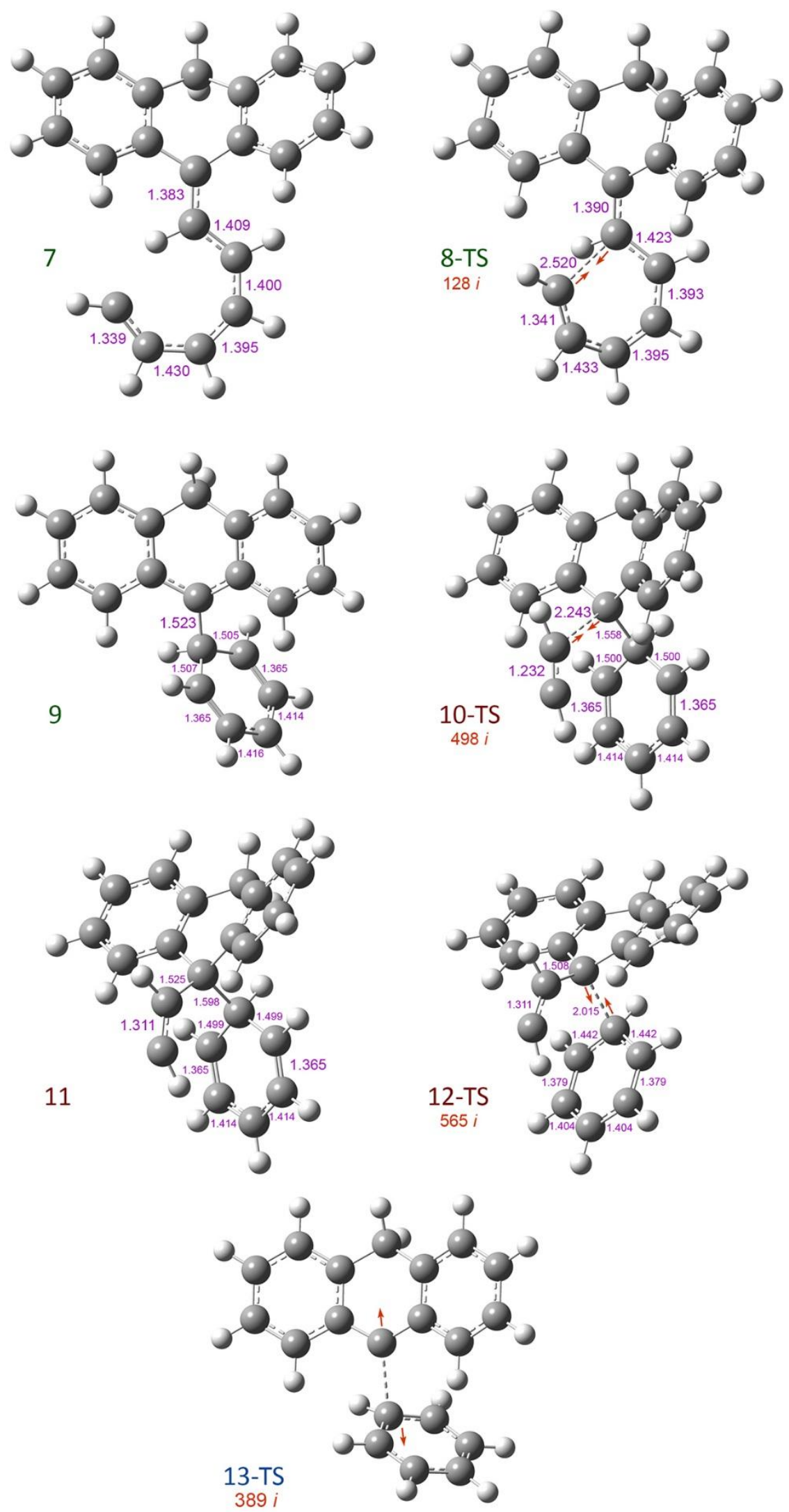

Figure S13. Optimized molecular structures of the stationary points 7 to 13-TS for the tricyclic triplet carbene-catalyzed reaction. The interatomic distances are in angstroms. For each transition state, the imaginary frequency is shown; directions of atomic movements corresponding to imaginary frequencies are shown by red arrows; UPBE1PBE/6-31G(d) level. 

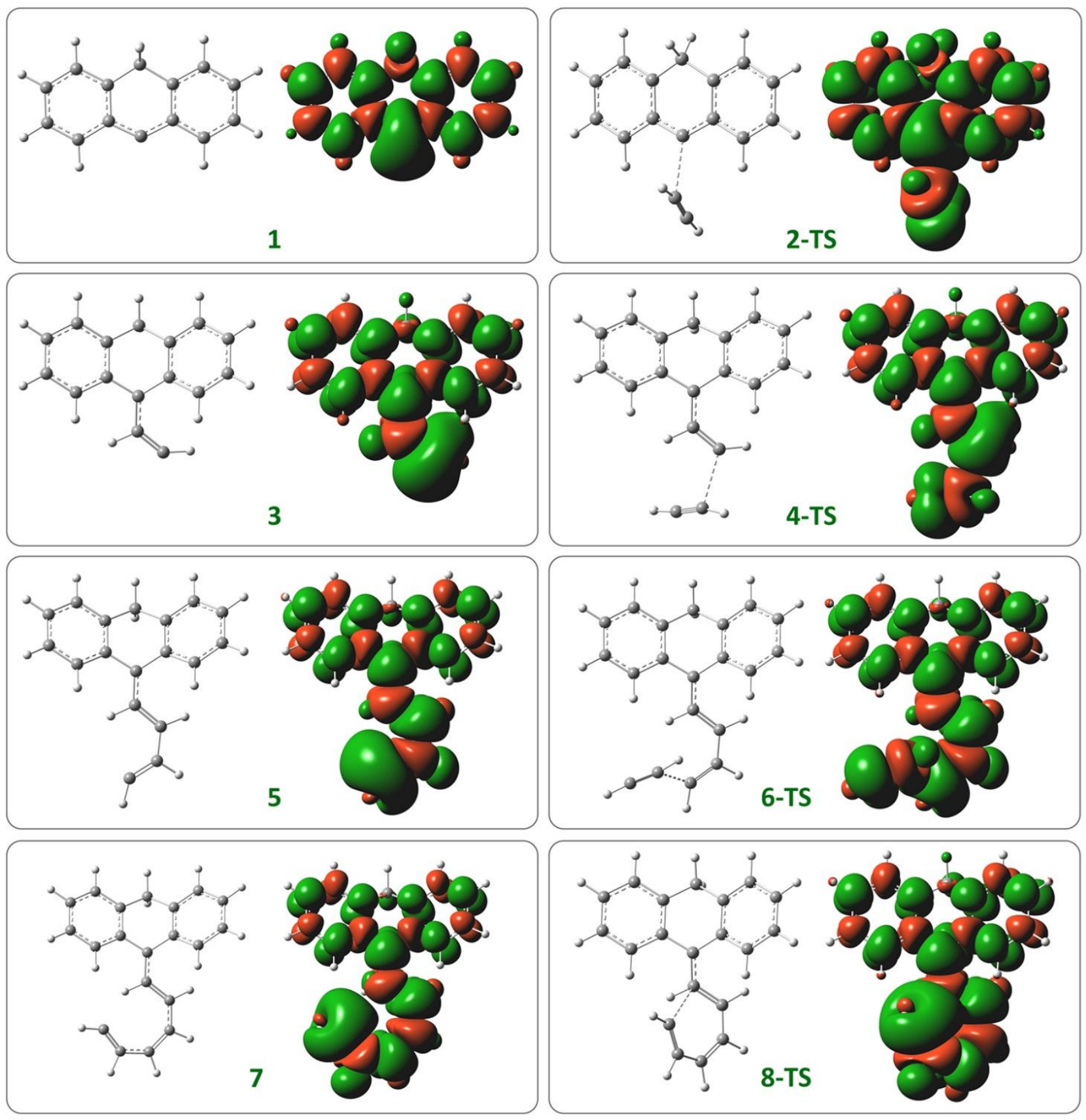

Figure S14. Spin density distributions in the stationary points $\mathbf{1}-\mathbf{8}$-TS for $\mathrm{C}_{14} \mathrm{H}_{10}$ carbocatalyst; UPBE1PBE/6-31G(d) level. 

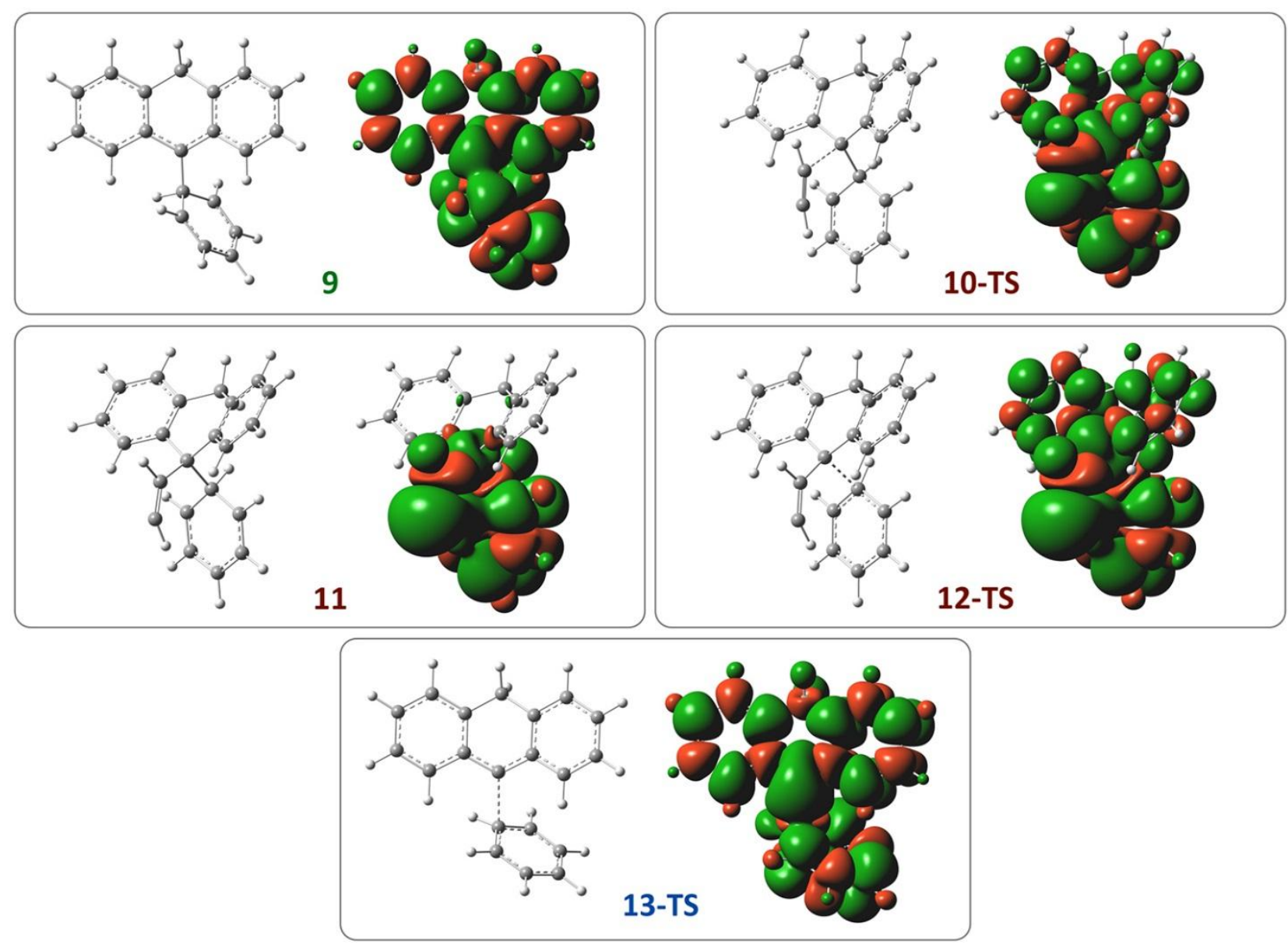

Figure S15. Spin density distributions in the stationary points 9 - 13-TS for $\mathrm{C}_{14} \mathrm{H}_{10}$ carbocatalyst; UPBE1PBE/6-31G(d) level. 


\section{Acetylene trimerization with $\mathrm{C}_{37} \mathrm{H}_{15}$ and $\mathrm{C}_{19} \mathrm{H}_{11}$ (olympicenyl) monoradical carbocatalysts}

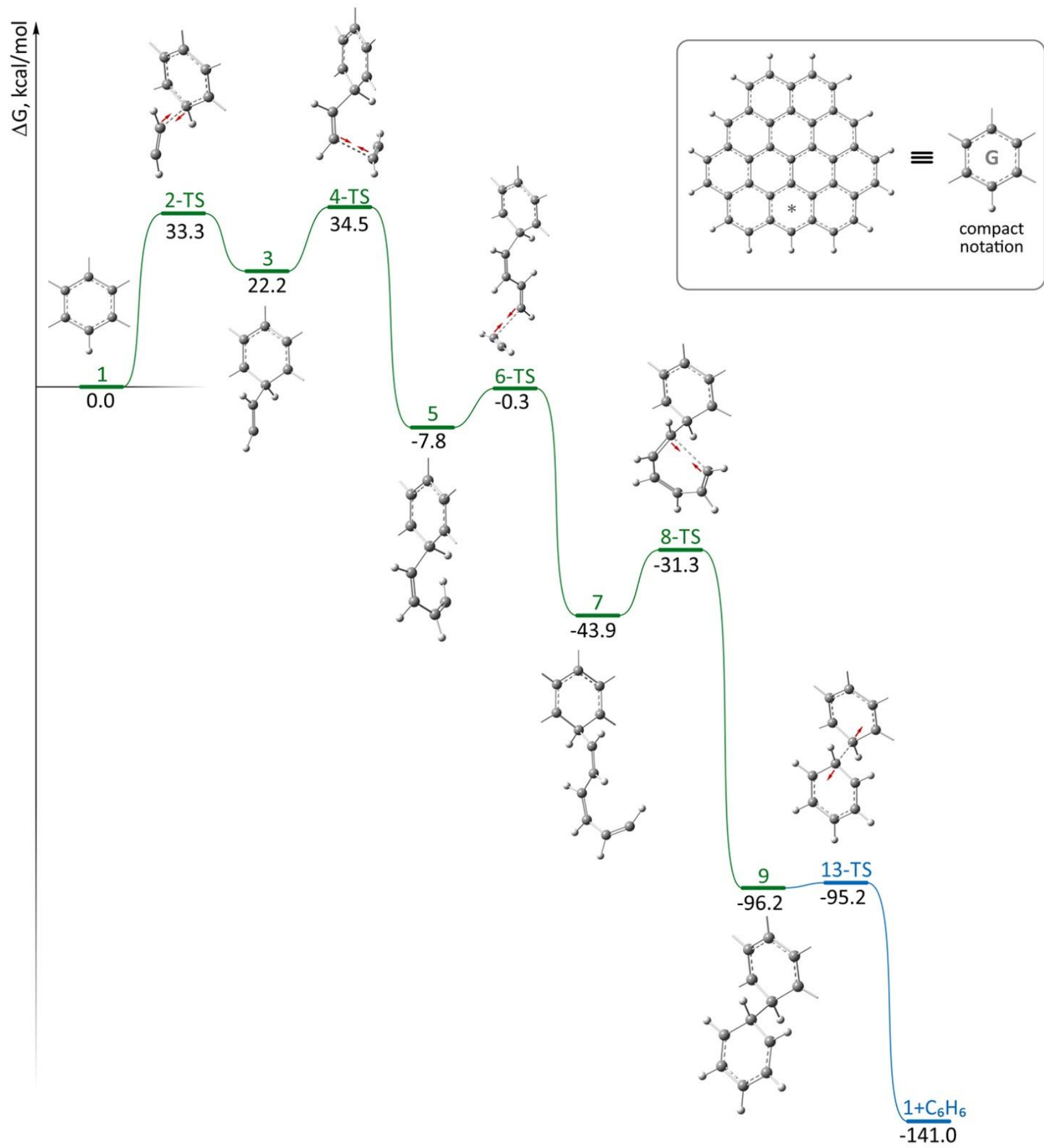

Figure S16. Free energy profile of acetylene cyclotrimerization reaction $(\Delta \mathrm{G})$ with $\mathrm{C}_{37} \mathrm{H}_{15}$ polyaromatic hydrocarbon as a catalyst; single point calculations at UPBE1PBE/6-311++G(d,p) level for geometries optimized at UPBE1PBE/6-31G(d) level. 


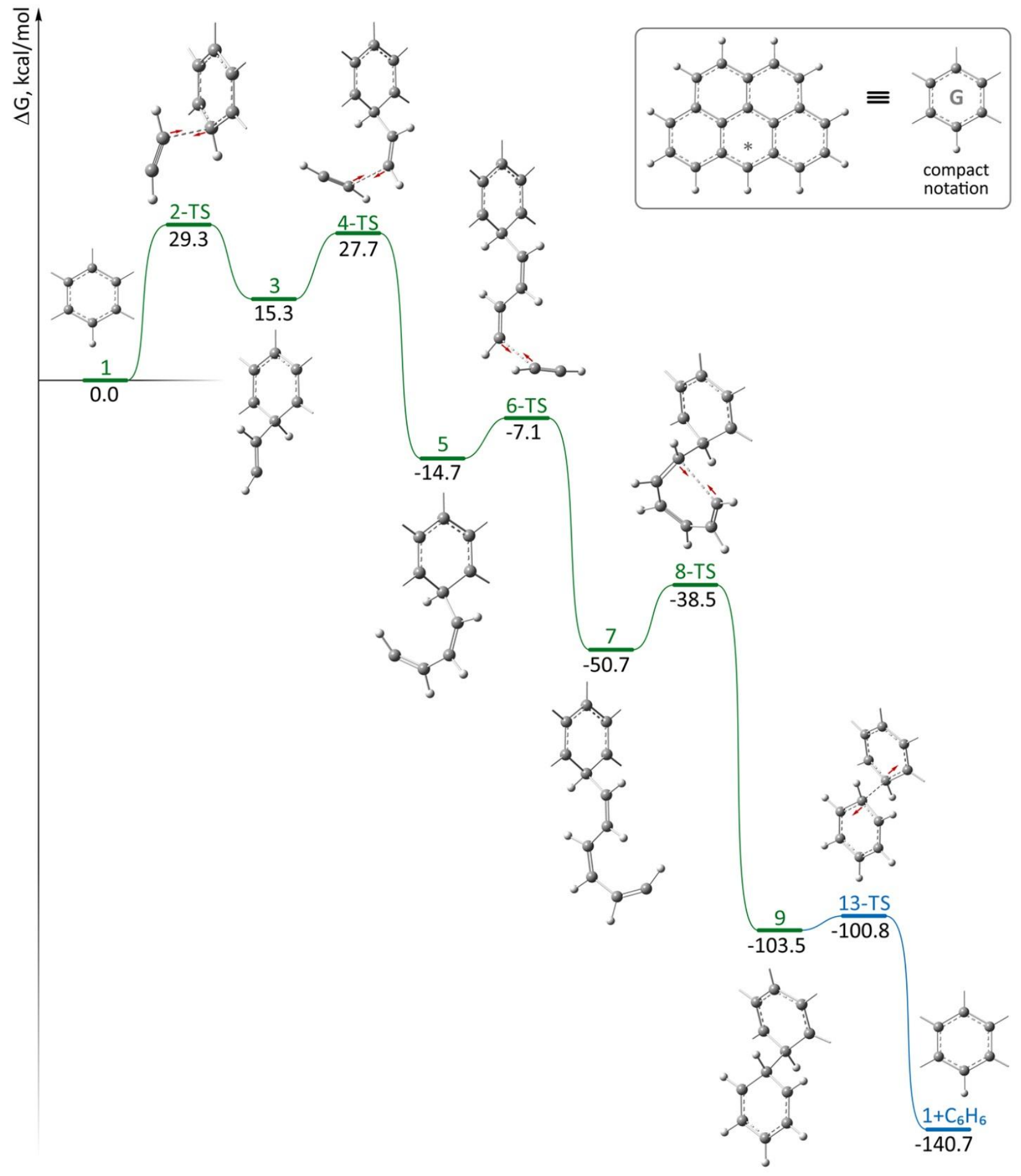

Figure S17. Free energy profile of acetylene cyclotrimerization reaction $(\Delta \mathrm{G})$ with $\mathrm{C}_{19} \mathrm{H}_{11}$ polyaromatic hydrocarbon (olympicenyl radical) as a catalyst; single point calculations at UPBE1PBE/6-311++G(d,p) level for geometries optimized at UPBE1PBE/6-31G(d) level. 

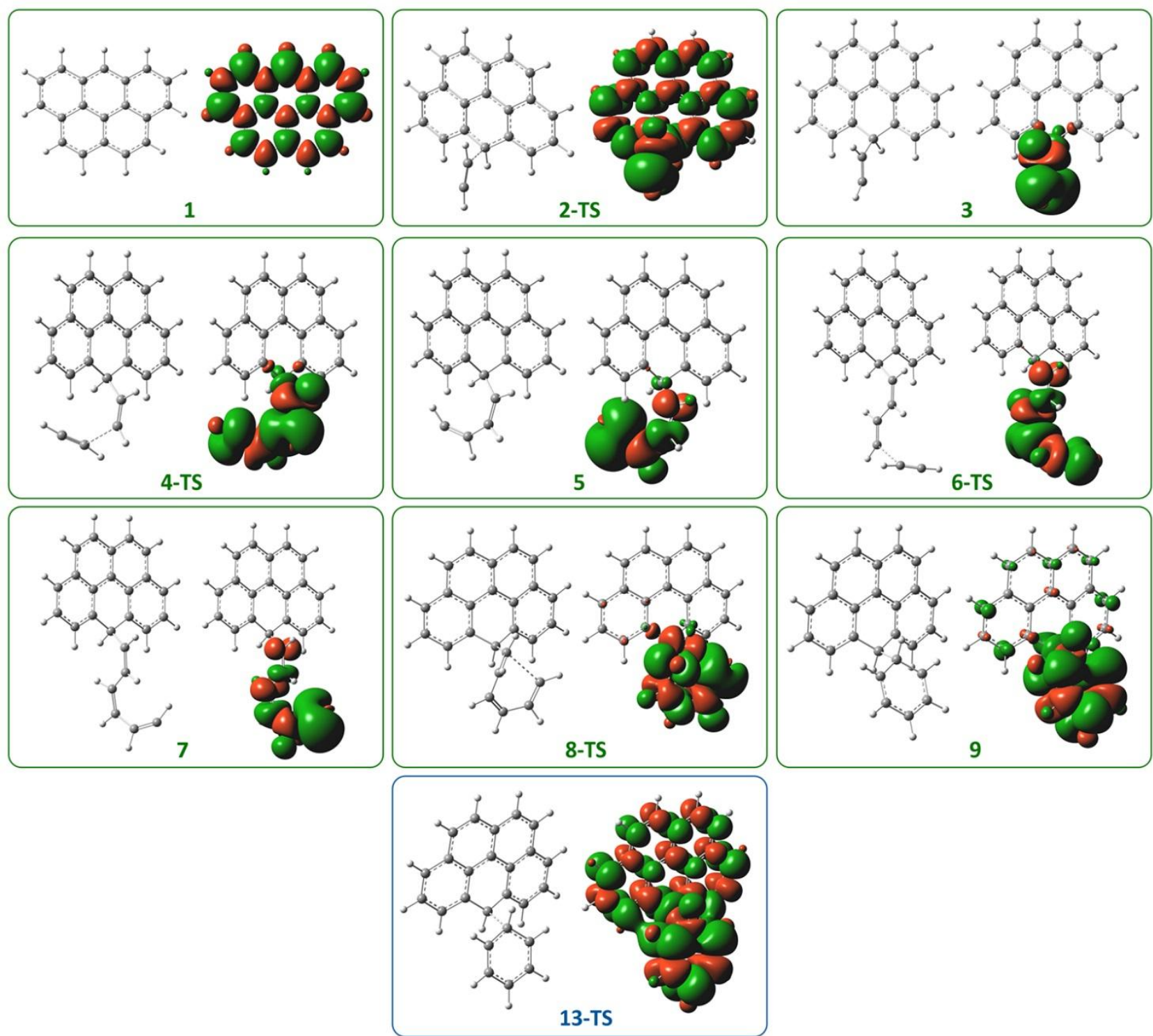

Figure S18. Spin density distributions in the stationary points $\mathbf{1}-\mathbf{1 3 - T S}$ for $\mathrm{C}_{19} \mathrm{H}_{11}$ carbocatalyst; UPBE1PBE/6-31G(d) level. 


\section{Acetylene trimerization with non-Kekulé $\mathrm{C}_{25} \mathrm{H}_{12}$ carbocatalyst}

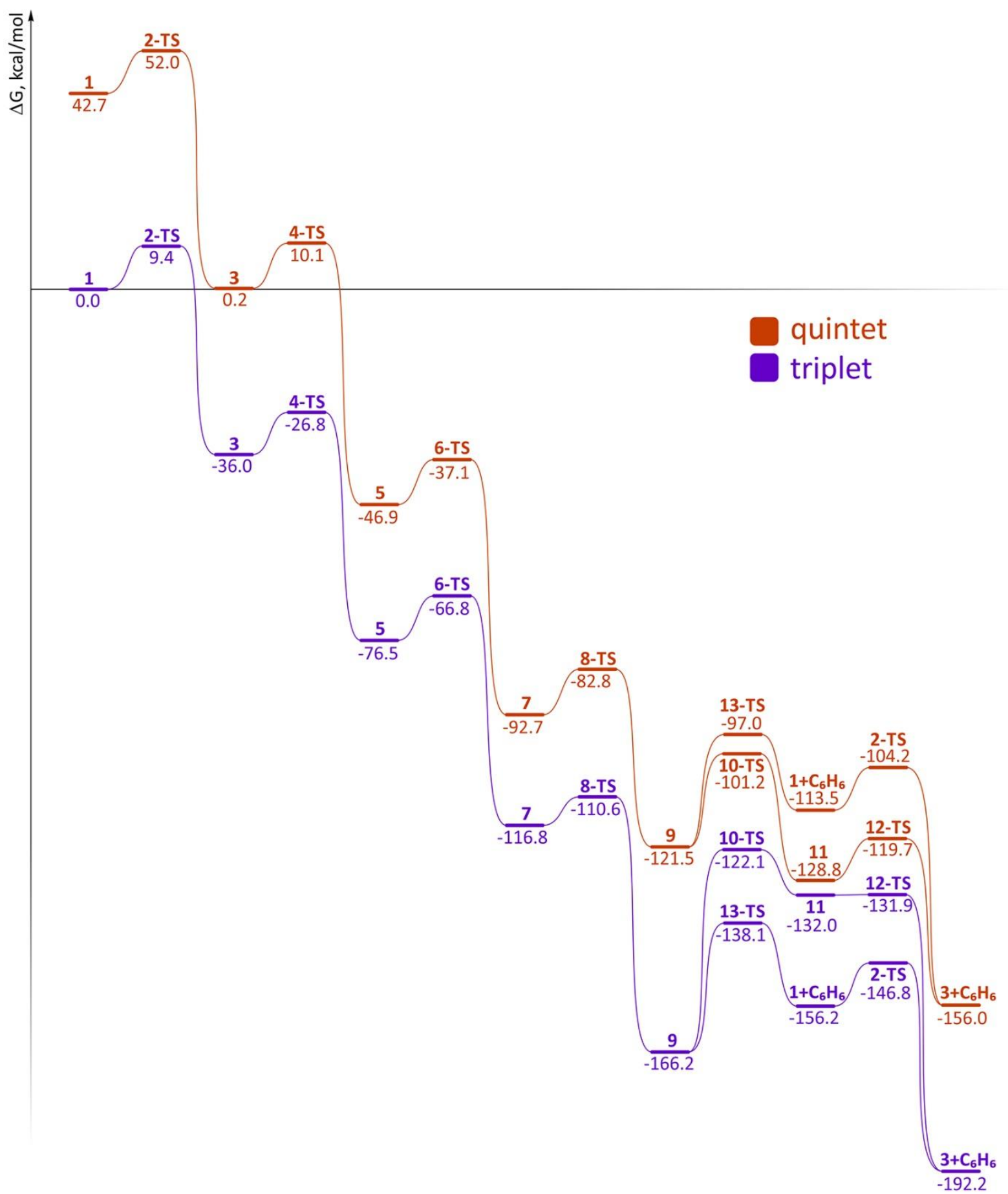

Figure S19. Free energy profile of acetylene cyclotrimerization reaction $(\Delta \mathrm{G})$ with $\mathrm{C}_{25} \mathrm{H}_{12}$ polyaromatic hydrocarbon as a catalyst in triplet and quintet spin states; UPBE1PBE/6-31G(d) level. 


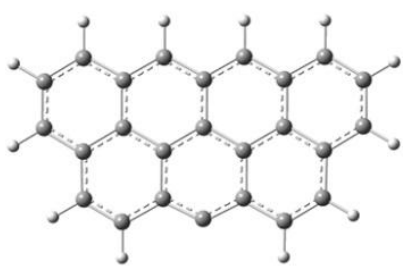

1

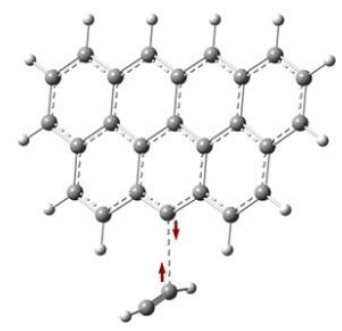

2-TS

$260 i$

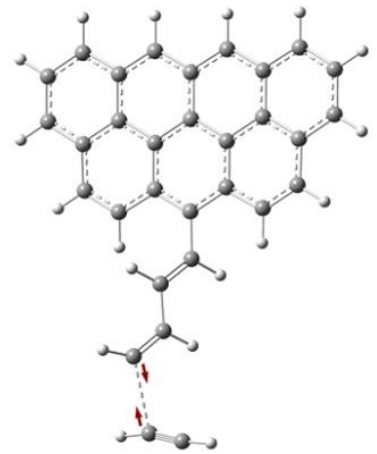

6-TS

$288 i$

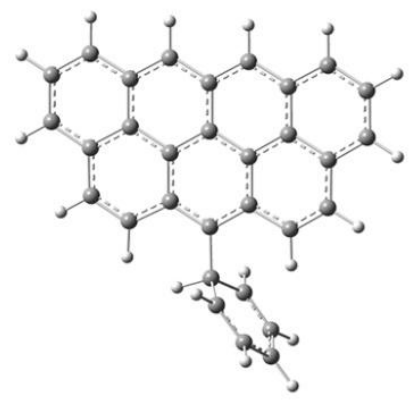

9

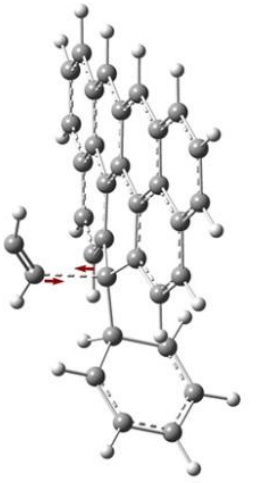

10-TS

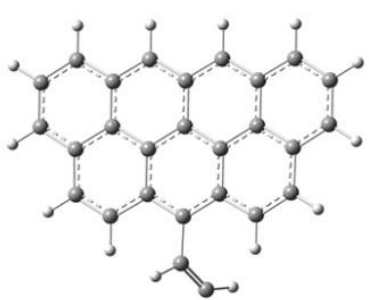

3

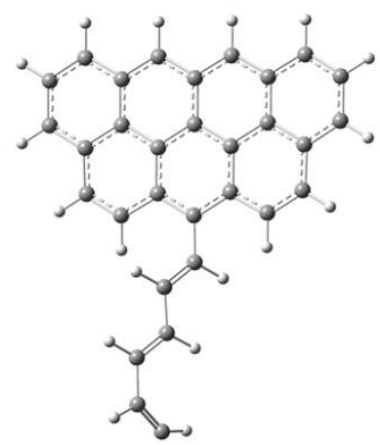

7

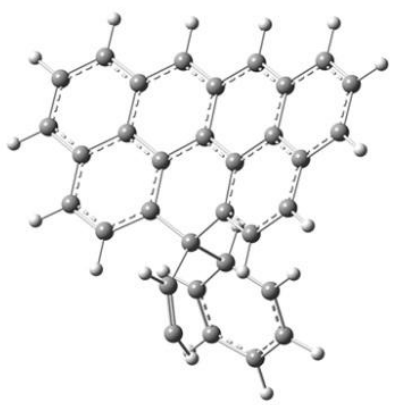

11

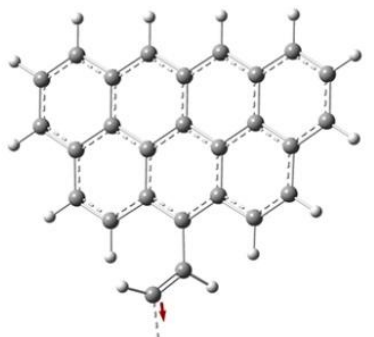

4-TS

$247 i$

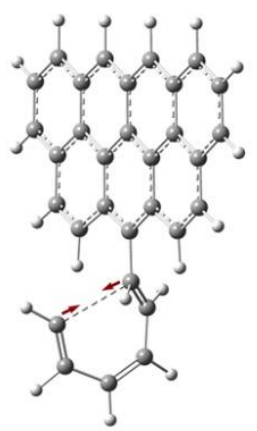

8-TS

$188 i$

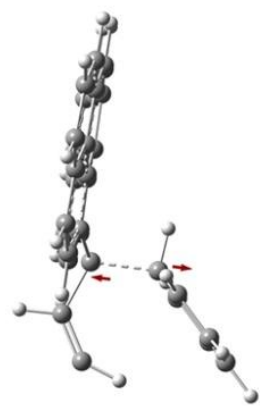

12-TS

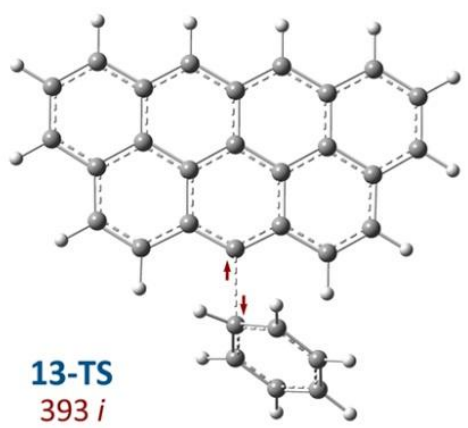

$268 i$

Figure S20. Optimized molecular structures of stationary points $\mathbf{1}-\mathbf{1 3 - T S}$ for the $\mathrm{C}_{25} \mathrm{H}_{12}$ polyaromatic hydrocarbon in triplet spin state. For each transition state, the imaginary frequency is shown; directions of atomic movements corresponding to imaginary frequencies are shown by red arrows; UPBE1PBE/6-31G(d) level. 


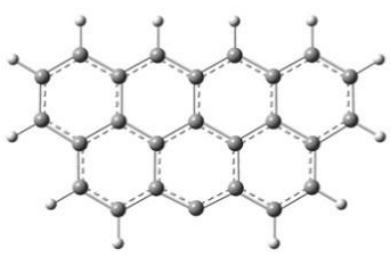

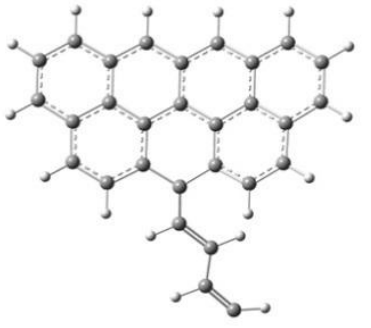

5

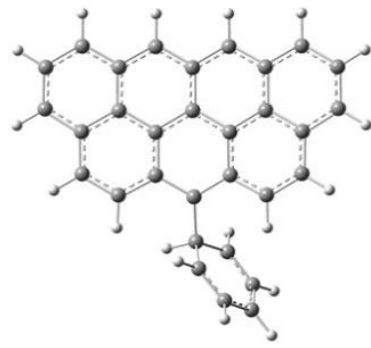

9

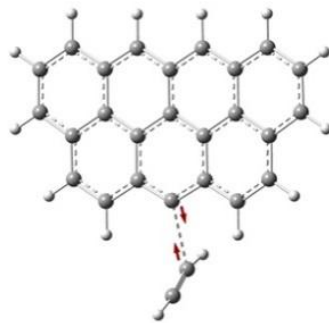

2-TS

$2-T S$
$278 i$

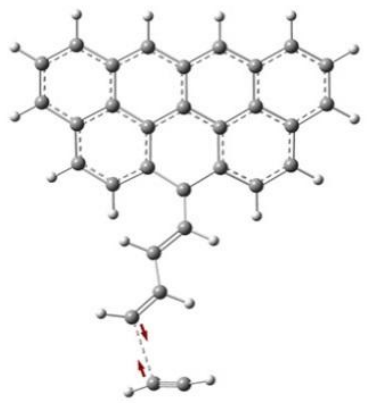

6-TS

$296 i$

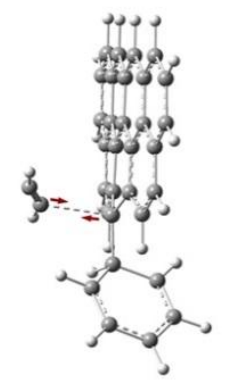

10-TS

$529 i$

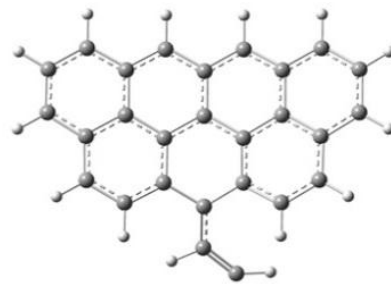

3

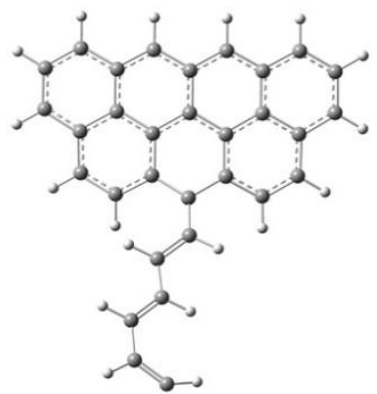

7

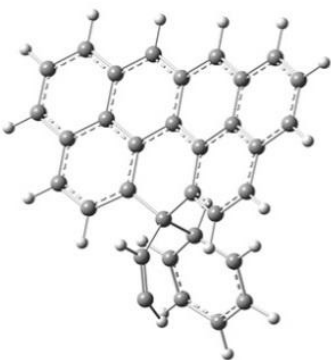

11

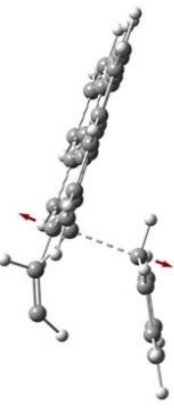

12-TS

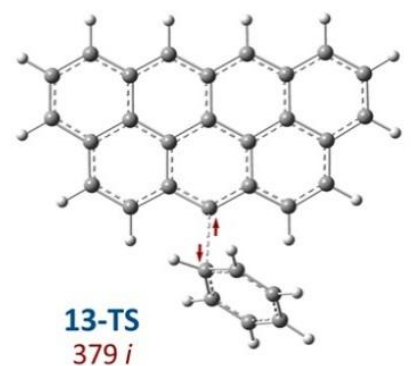

Figure S21. Optimized molecular structures of stationary points $\mathbf{1}-\mathbf{1 3 - T S}$ for the $\mathrm{C}_{25} \mathrm{H}_{12}$ polyaromatic hydrocarbon in quintet spin state. For each transition state, the imaginary frequency is shown; directions of atomic movements corresponding to imaginary frequencies are shown by red arrows; UPBE1PBE/6-31G(d) level. 


\section{Acetylene trimerization with phenyl monoradical as a carbocatalyst}

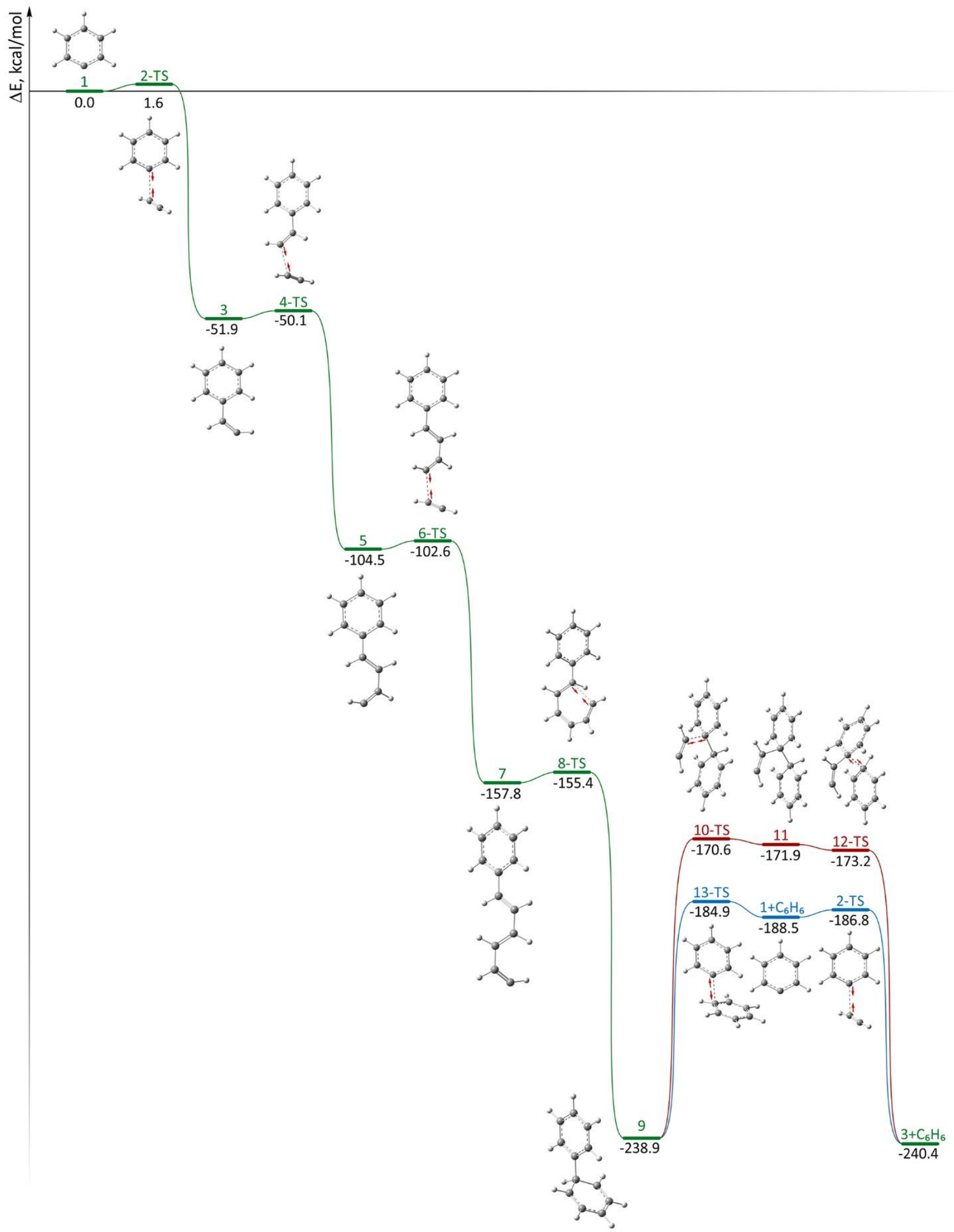

Figure S22. Total energy profile $(\Delta \mathrm{E})$ of acetylene cyclotrimerization reaction with $\mathrm{C}_{6} \mathrm{H}_{5}$ monoradical as a catalyst; UPBE1PBE/6-31G(d) level. 


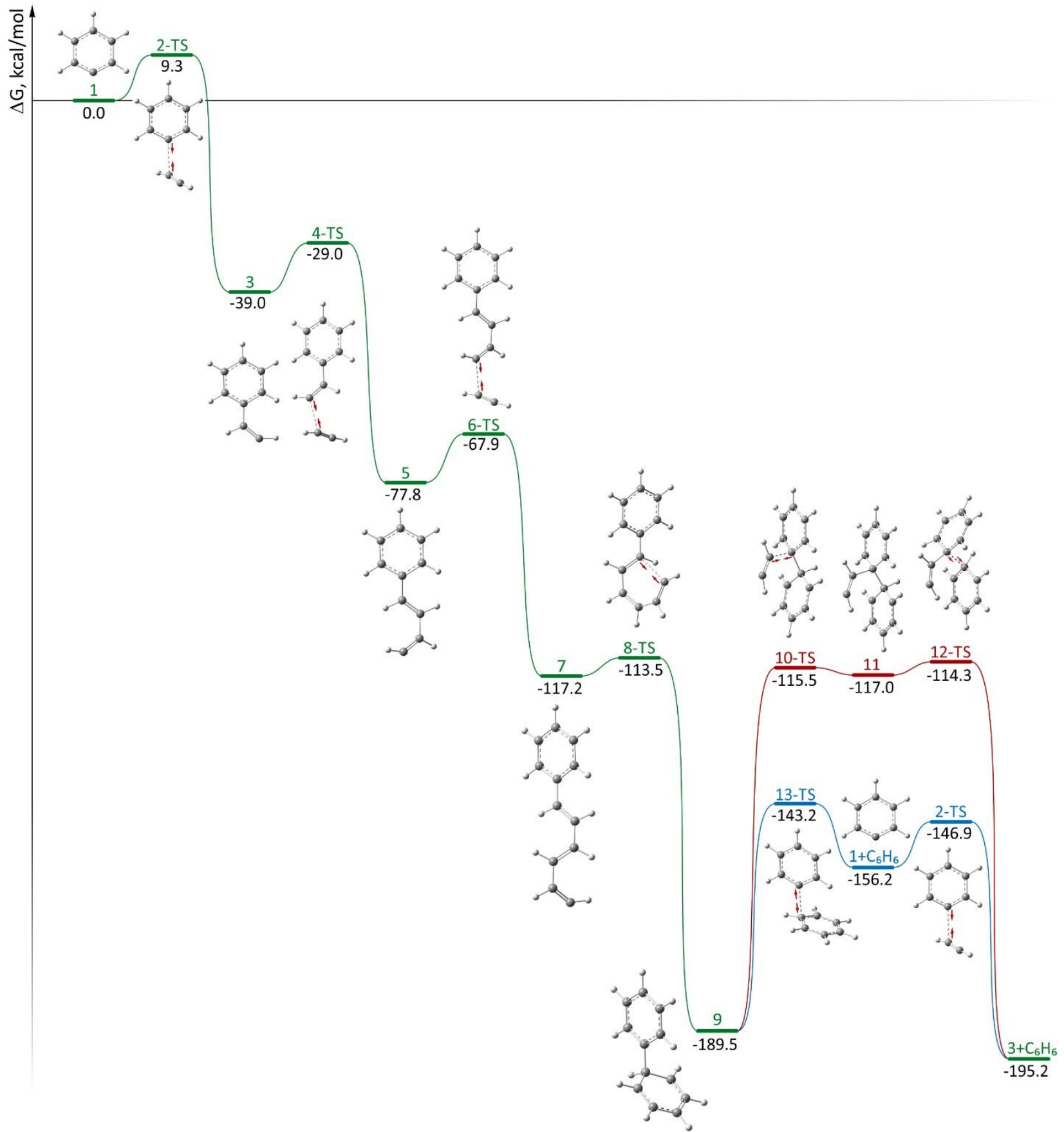

Figure S23. Free energy profile $(\Delta \mathrm{G})$ of acetylene cyclotrimerization reaction with $\mathrm{C}_{6} \mathrm{H}_{5}$ monoradical as a catalyst; UPBE1PBE/6-31G(d) level. 


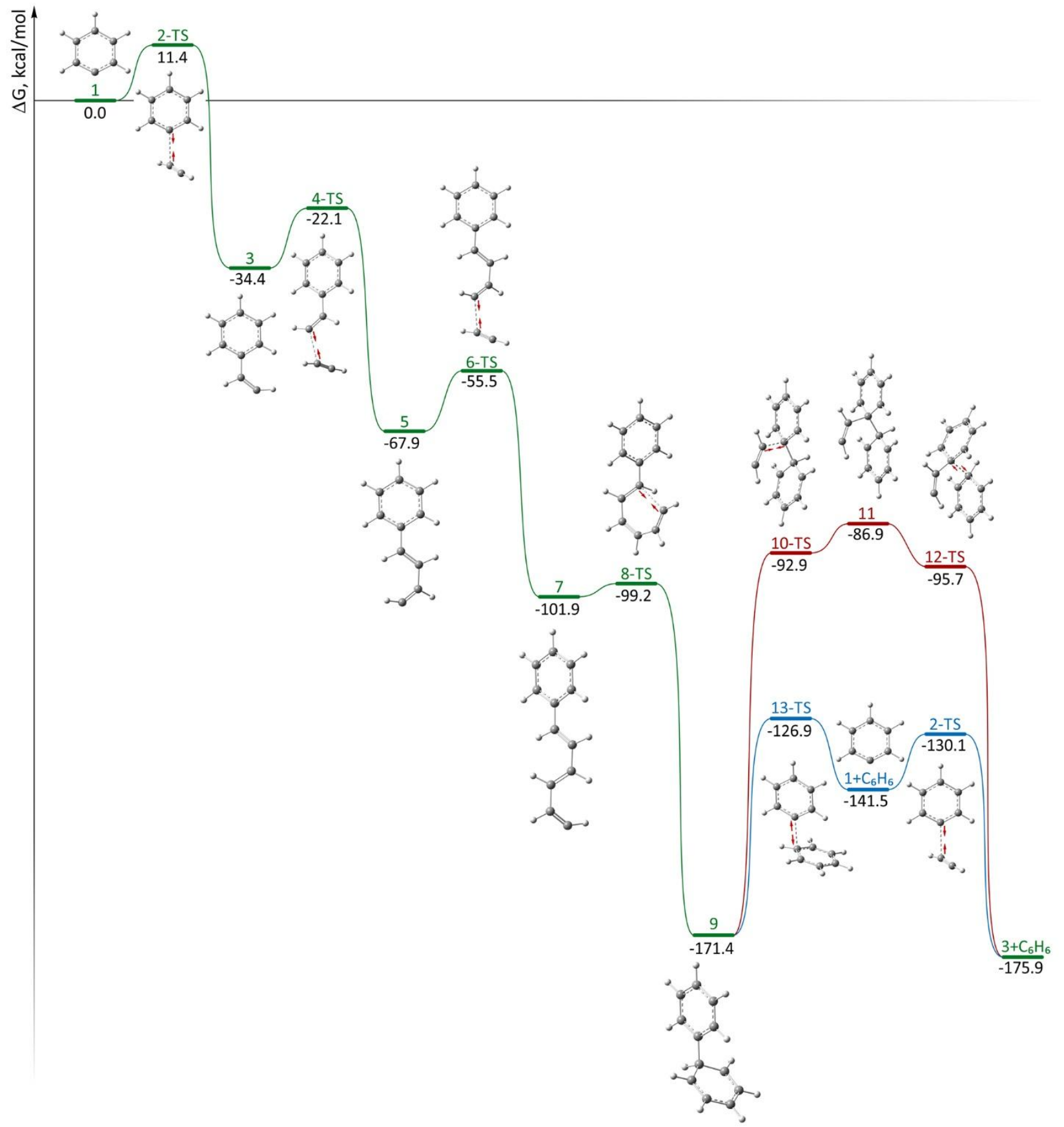

Figure S24. Free energy profile $(\Delta \mathrm{G})$ of acetylene cyclotrimerization reaction with $\mathrm{C}_{6} \mathrm{H}_{5}$ monoradical as a catalyst; single point calculations at UPBE1PBE/6-311++G(d,p) level for geometries optimized at UPBE1PBE/6-31G(d) level. 


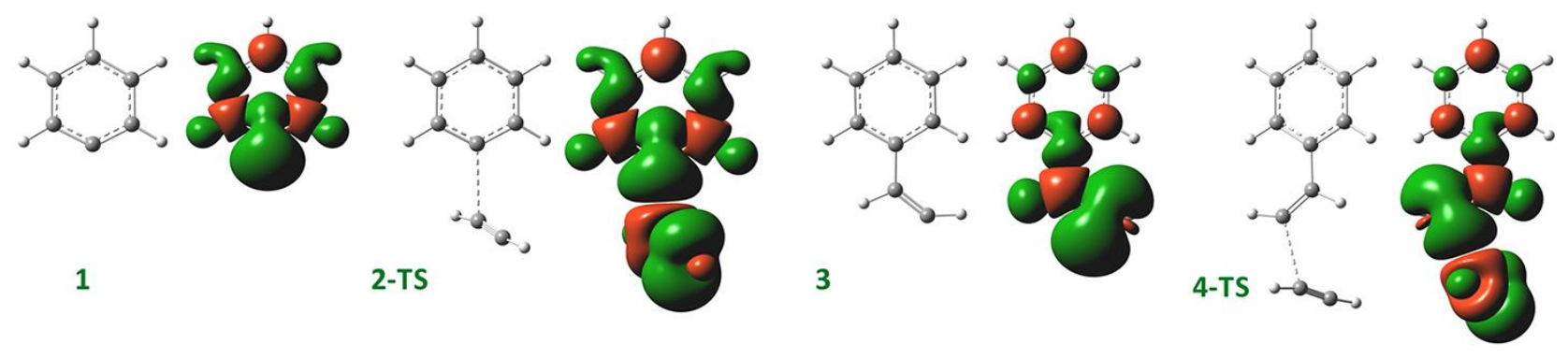

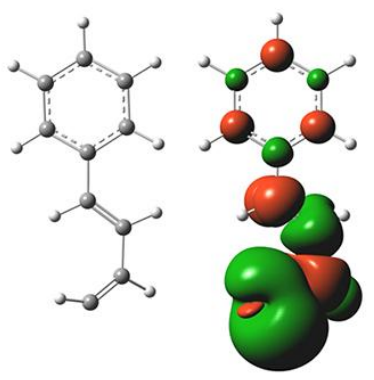

5

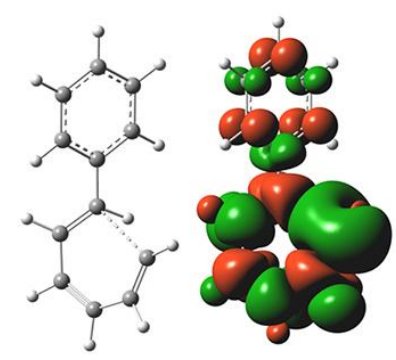

8-TS

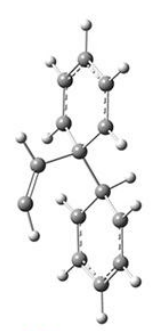

11

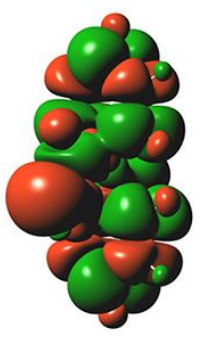

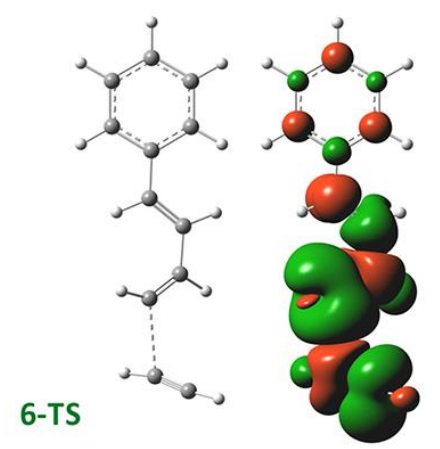
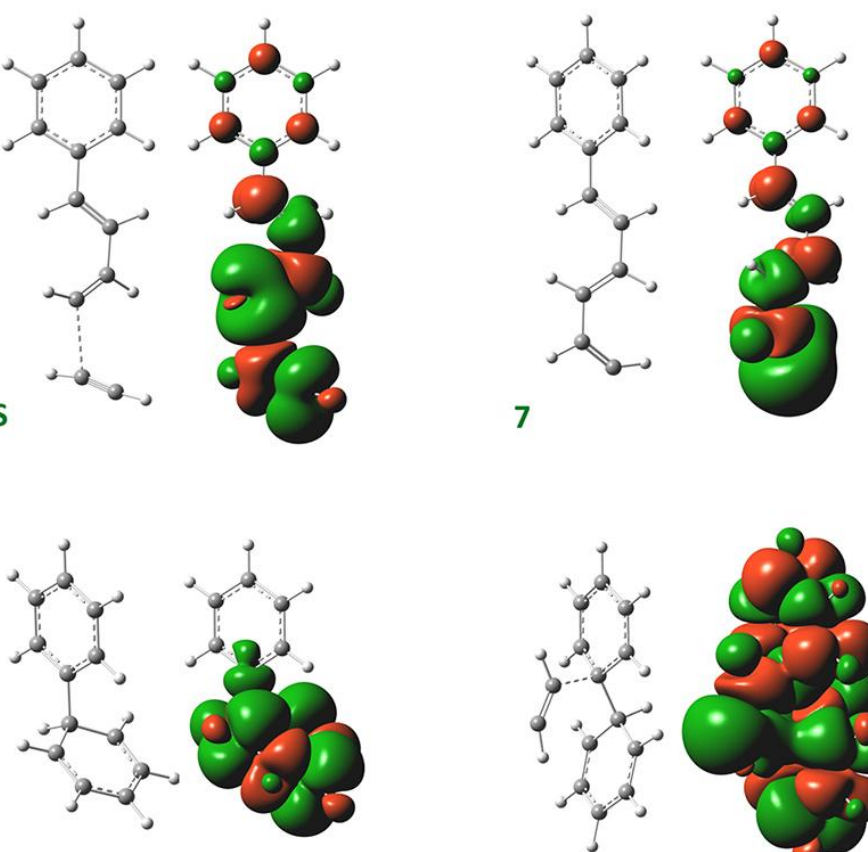

9

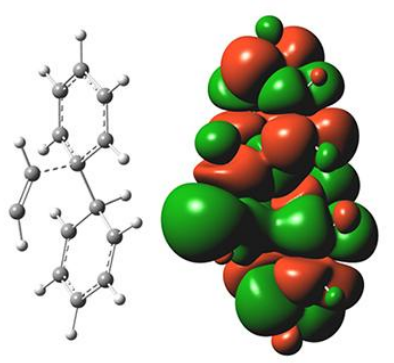

10-TS

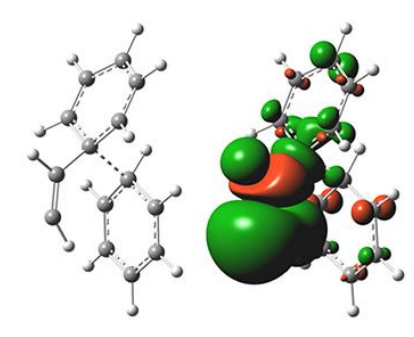

12-TS

Figure S25. Spin density distributions in the stationary points $\mathbf{1}-\mathbf{1 3 - T S}$ for $\mathrm{C}_{6} \mathrm{H}_{5}$ carbocatalyst; UPBE1PBE/6-31G(d) level. 


\section{Evaluation of the theoretical calculations accuracy for different basis sets and theory levels}

Table S1. Total energy values $(\Delta \mathrm{E})$ calculated for each stage of acetylene cyclotrimerization process with $\mathrm{C}_{14} \mathrm{H}_{10}$ carbene as a carbocatalyst at the different levels of theory.

\begin{tabular}{|c|c|c|c|c|c|c|c|c|c|c|c|c|c|c|}
\hline Level of theory & 1 & 2-TS & 3 & 4-TS & 5 & 6-TS & 7 & 8-TS & 9 & $10-\mathrm{TS}$ & 11 & 12-TS & $\mathrm{NG}$ & $1+\mathrm{C}_{6} \mathrm{H}_{6}$ \\
\hline UPBE1PBE/6-31G(d) & 0.0 & 1.2 & -52.0 & -49.8 & -108.9 & $\mid-107.2$ & -160.9 & -159.8 & -208.3 & $\mid-187.4$ & -219.4 & -210.9 & 823 & 1885 \\
\hline & 0.0 & 3.0 & -47.0 & -43.4 & -98.8 & -95.0 & & & & & & & & 29 \\
\hline UM062X/6-311++G(d,p $)^{\dagger}$ & 0.0 & 2.4 & -43.5 & -39.8 & -89.7 & -86.2 & -130.8 & -130. & -175.4 & $\mid-156.0$ & -185.2 & -176.5 & -151.9 & -156.8 \\
\hline
\end{tabular}

$\dagger$ - single point calculations of molecular structures optimized at the UPBE1PBE/6-31G(d) level.

Table S2. Total energy values $(\Delta \mathrm{E})$ of $(\mathbf{9} \rightarrow \mathbf{1 0}$-TS $\rightarrow \mathbf{1 1} \rightarrow$ 12-TS; 13-TS $\rightarrow$ 1) potential energy profile segments (see Figures 1 and 2 ) for $\mathrm{C}_{6}$ carbocatalyst at the different theory levels.

\begin{tabular}{|c|c|c|c|c|c|c|c|}
\hline Level of theory & 1 & 9 & 10-TS & 11 & 12-TS & 13-TS & 1+benzene \\
\hline UPBE1PBE/6-31G(d) & 0.0 & -213.5 & -194.0 & -216.8 & -213.0 & -184.6 & -188.5 \\
\hline UB3LYP/6-31G(d) ${ }^{\dagger}$ & 0.0 & -190.3 & -167.0 & -185.5 & -183.9 & -165.0 & -170.5 \\
\hline UPBE1PBE/6-311+G(2d,p $)^{\dagger}$ & 0.0 & -197.6 & -176.2 & -197.0 & -193.7 & -169.3 & -174.1 \\
\hline UPBE1PBE/6-311+G(2d,p) GD3BJ ${ }^{\dagger}$ & 0.0 & -205.4 & -188.6 & -209.4 & -205.8 & -176.9 & -178.0 \\
\hline $\mathrm{UCCSD} / 6-31 \mathrm{G}(\mathrm{d})^{\dagger}$ & 0.0 & -178.3 & -155.1 & -180.1 & -171.5 & -148.1 & -155.5 \\
\hline $\mathrm{UCCSD}(\mathrm{T}) / 6-31 \mathrm{G}(\mathrm{d})^{\dagger}$ & 0.0 & -179.5 & -158.8 & -182.5 & -175.4 & -150.9 & -157.0 \\
\hline
\end{tabular}

$\dagger$ - single point calculations for geometries optimized at the UPBE1PBE/6-31G(d) level.
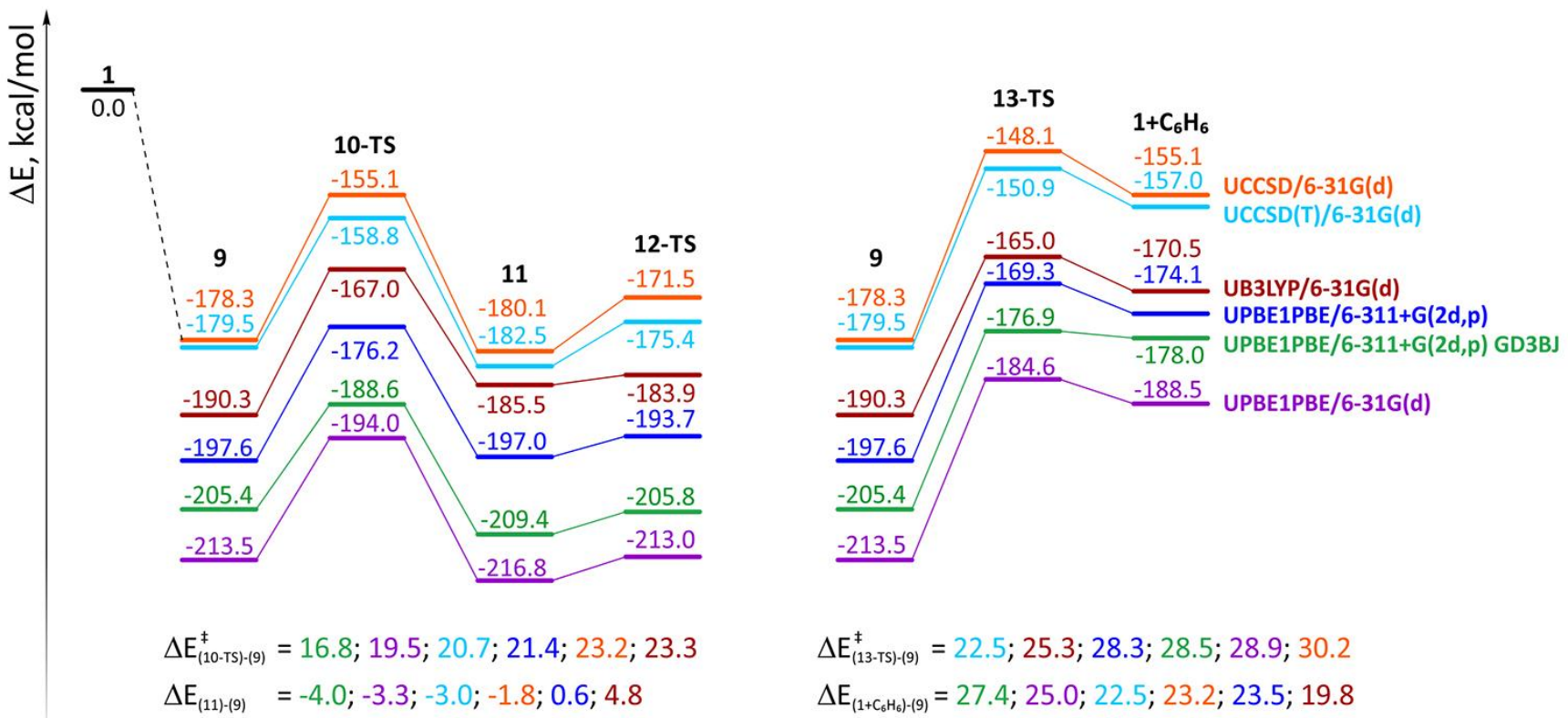

Figure S26. Segments of the total energy profile $(\mathbf{9} \rightarrow \mathbf{1 0}$-TS $\rightarrow \mathbf{1 1} \rightarrow \mathbf{1 2}$-TS and $\mathbf{9} \rightarrow \mathbf{1 3 - T S}$ $\rightarrow \mathbf{1}+\mathbf{C}_{6} \mathbf{H}_{6}$ see Figures 1 and 2 ) for $\mathrm{C}_{6}$ carbocatalyst calculated by different theory levels. 

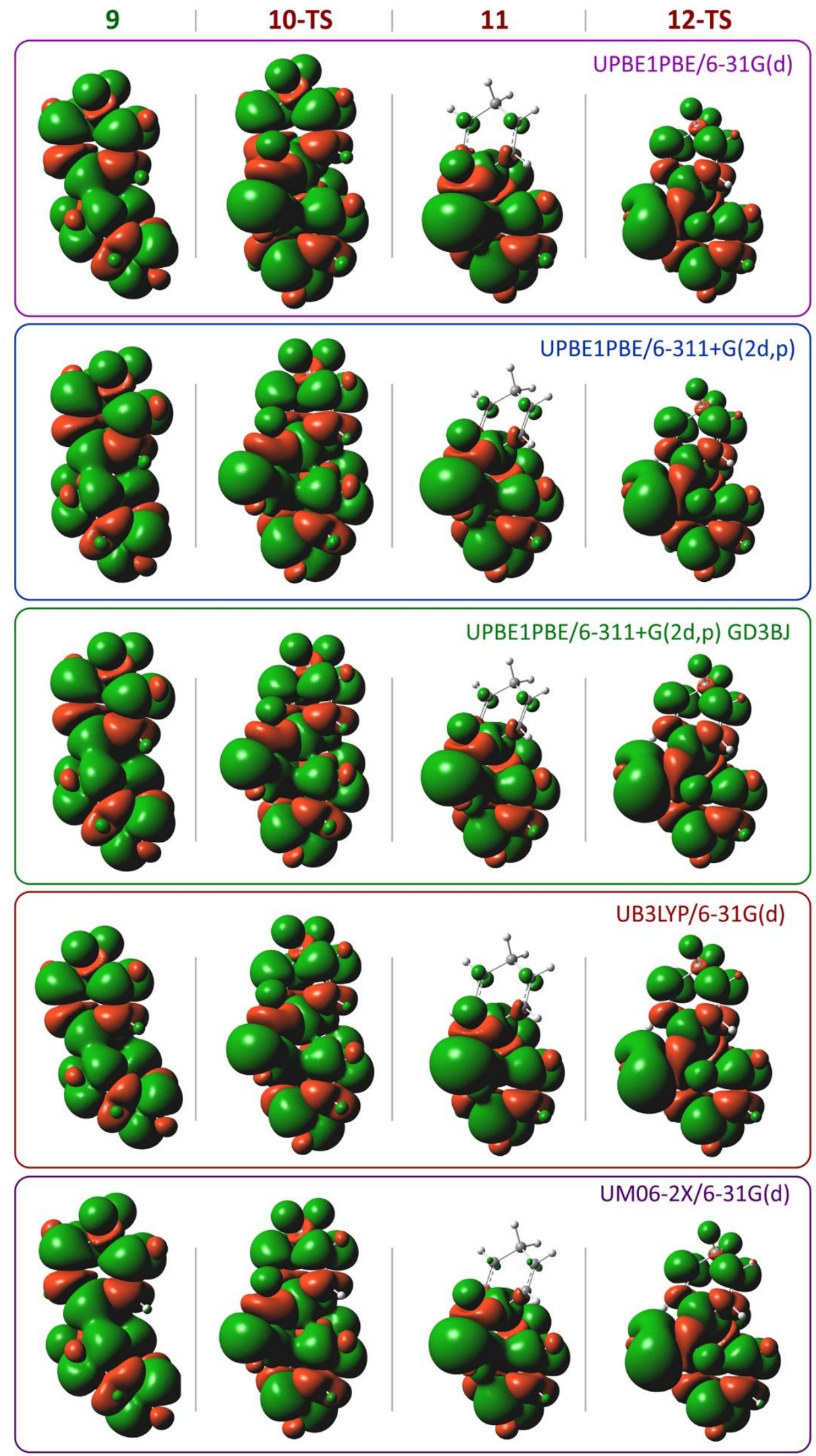

Figure S27. Spin density distributions in stationary points 9, 10-TS, 11 and 12-TS for the $\mathrm{C}_{6}$ model carbocatalyst calculated at the different theory levels. 


\section{Evaluation of graphene systems of different sizes}
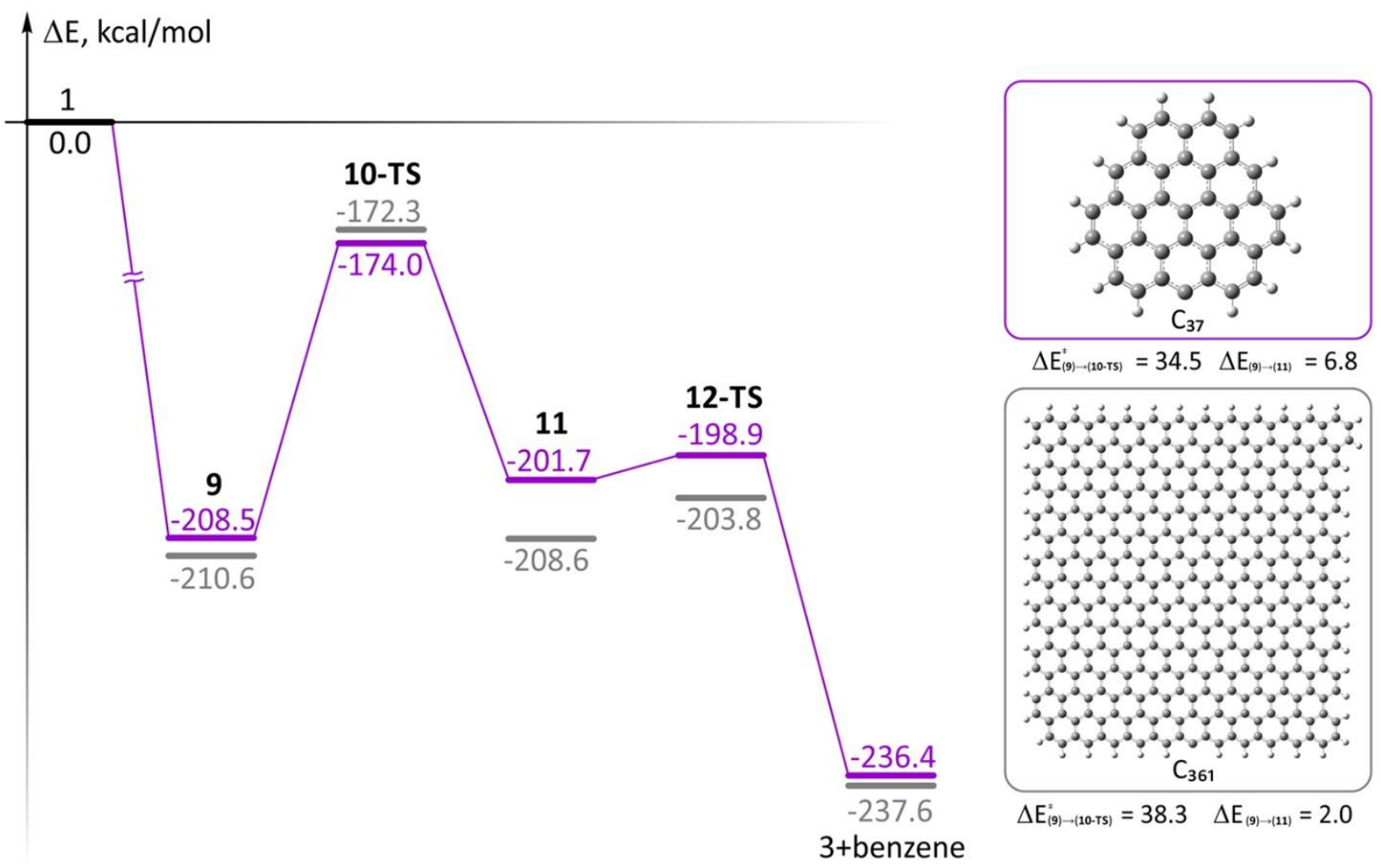

Figure S28. Comparative representation of $(\mathbf{9} \rightarrow \mathbf{1 0}$-TS $\rightarrow \mathbf{1 1} \rightarrow$ 12-TS $)$ PES segments for $\mathrm{C}_{361}$ and $\mathrm{C}_{37}$ carbocatalyst models. The $\mathrm{C}_{37}$ structures were optimized at the UPBE1PBE/6-31G(d) level, and single point calculations were performed for the $\mathrm{C}_{361}$ structures at the UPBE1PBE/6$31 \mathrm{G}(\mathrm{d})$ level. 


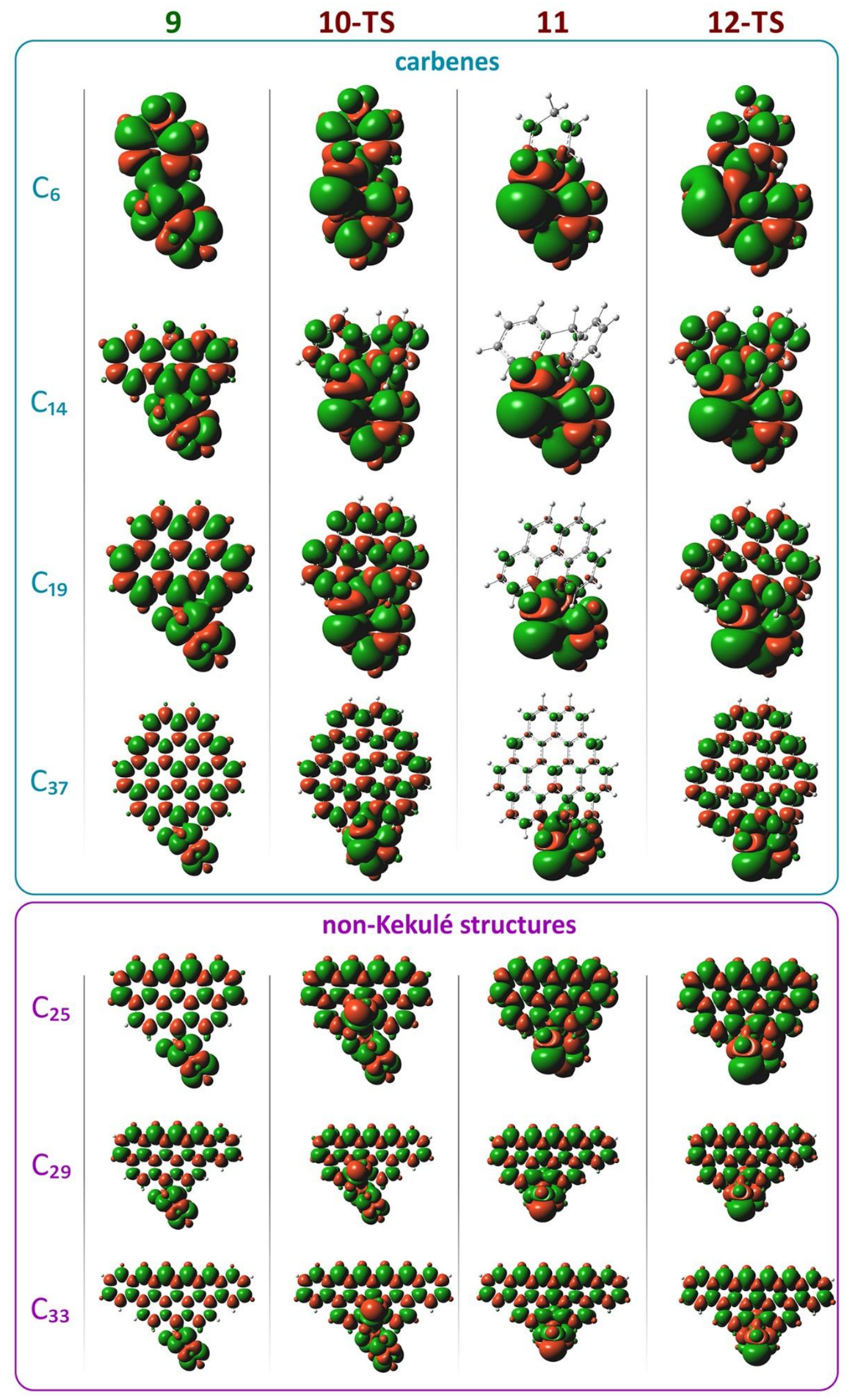

Figure S29. Spin density distributions in the stationary points 9, 10-TS, 11 and 12-TS for different model carbocatalysts; UPBE1PBE/6-31G(d) level. 


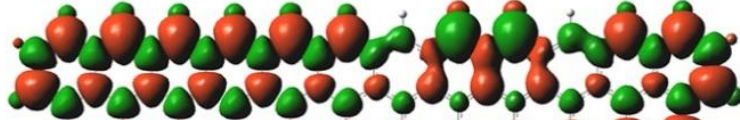
.000000000000000000

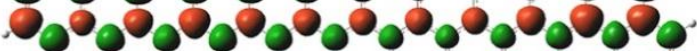

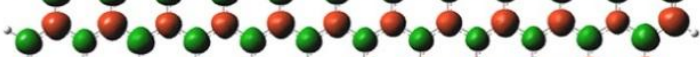

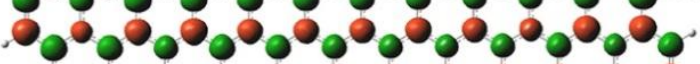

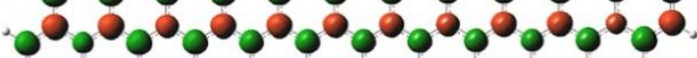
.000 .000

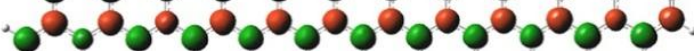

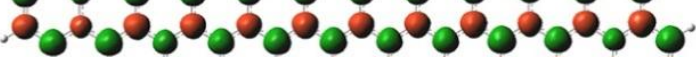

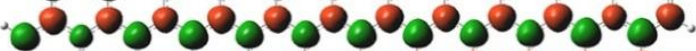

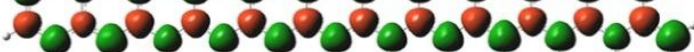
000000000000000000. .00000000000000000000

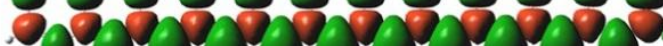

9

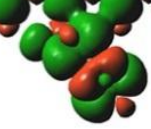
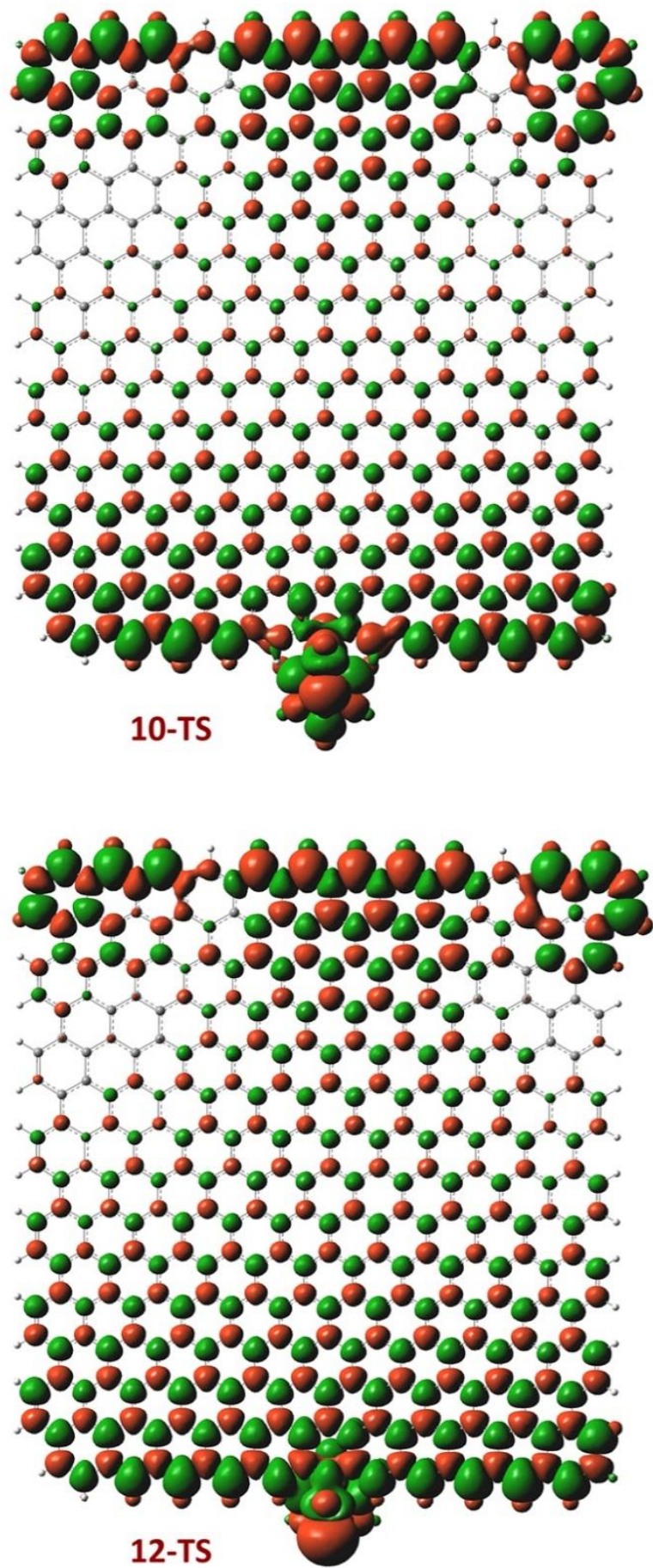

Figure S30. Spin density distributions in the stationary points 9, 10-TS, 11 and 12-TS for $\mathrm{C}_{361}$ model carbocatalyst; single point calculations at the UPBE1PBE/6-31G(d) level. 


\section{Experimental benzene synthesis}

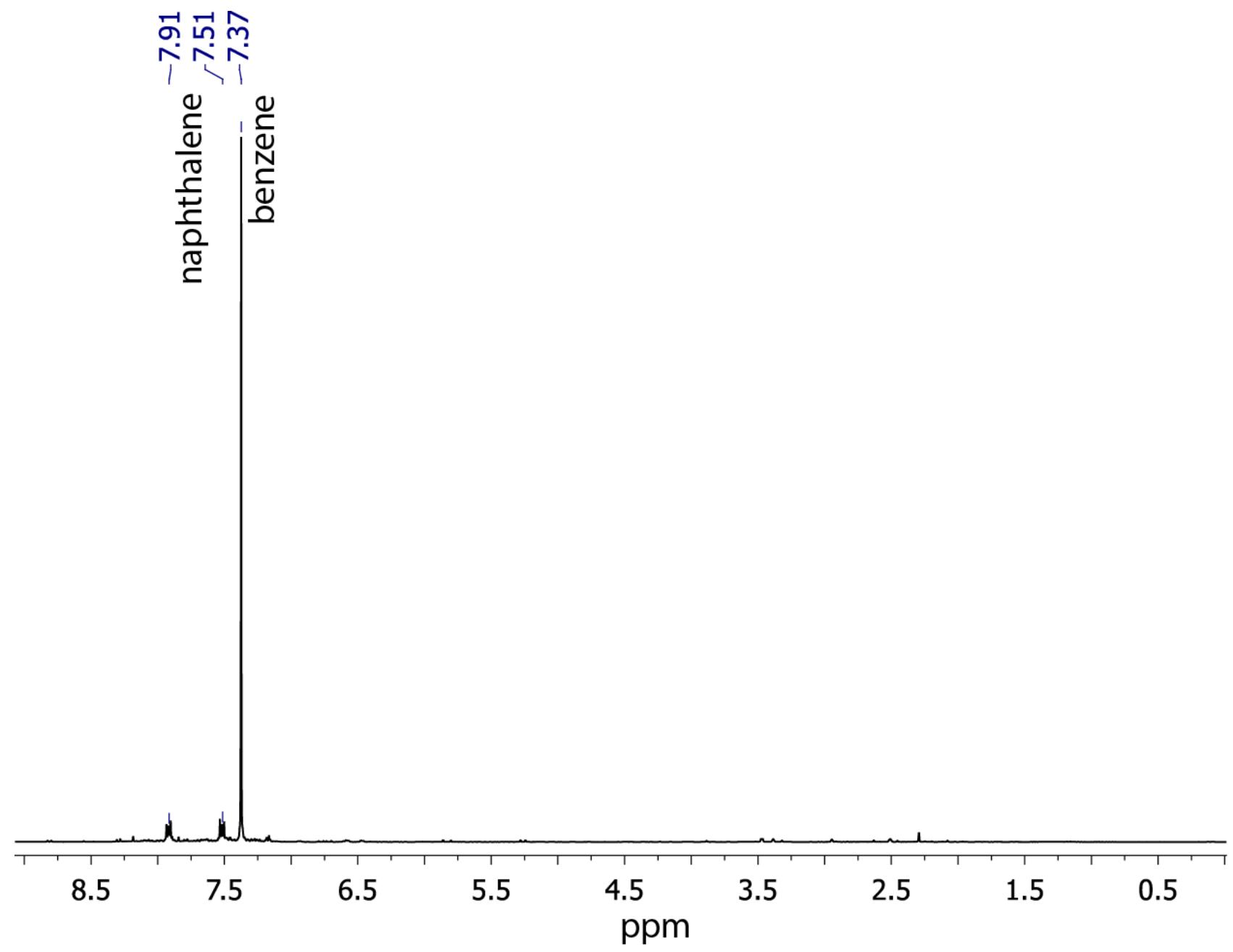

Figure S31. ${ }^{1} \mathrm{H}$ NMR spectrum of the products after completion of the reaction (DMSO- $\mathrm{d}_{6}$, $300.1 \mathrm{MHz}$ ). 


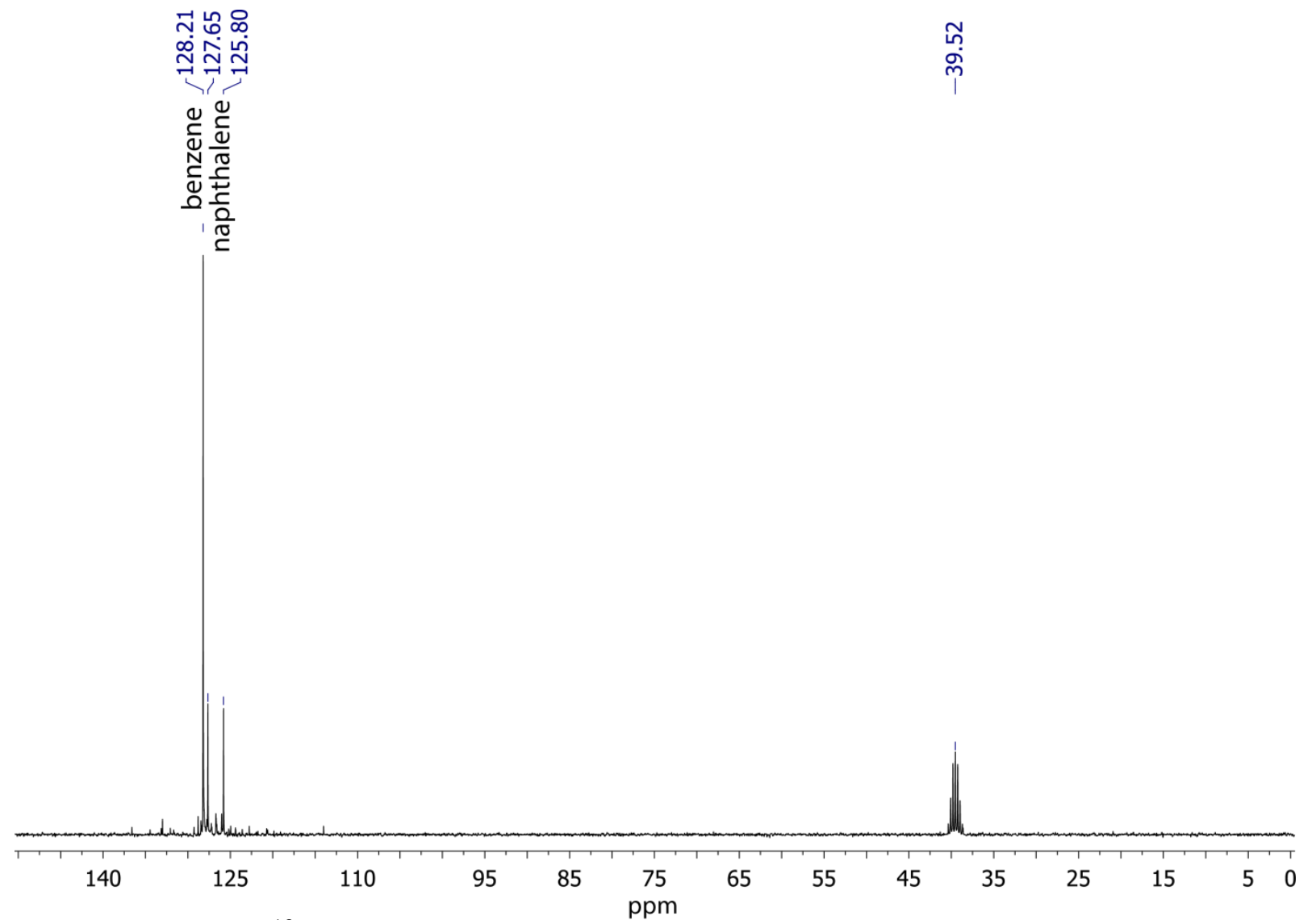

Figure S32. ${ }^{13} \mathrm{C}$ NMR spectrum of the products after completion of the reaction (DMSO- $\mathrm{d}_{6}$, $75 \mathrm{MHz}$ ).

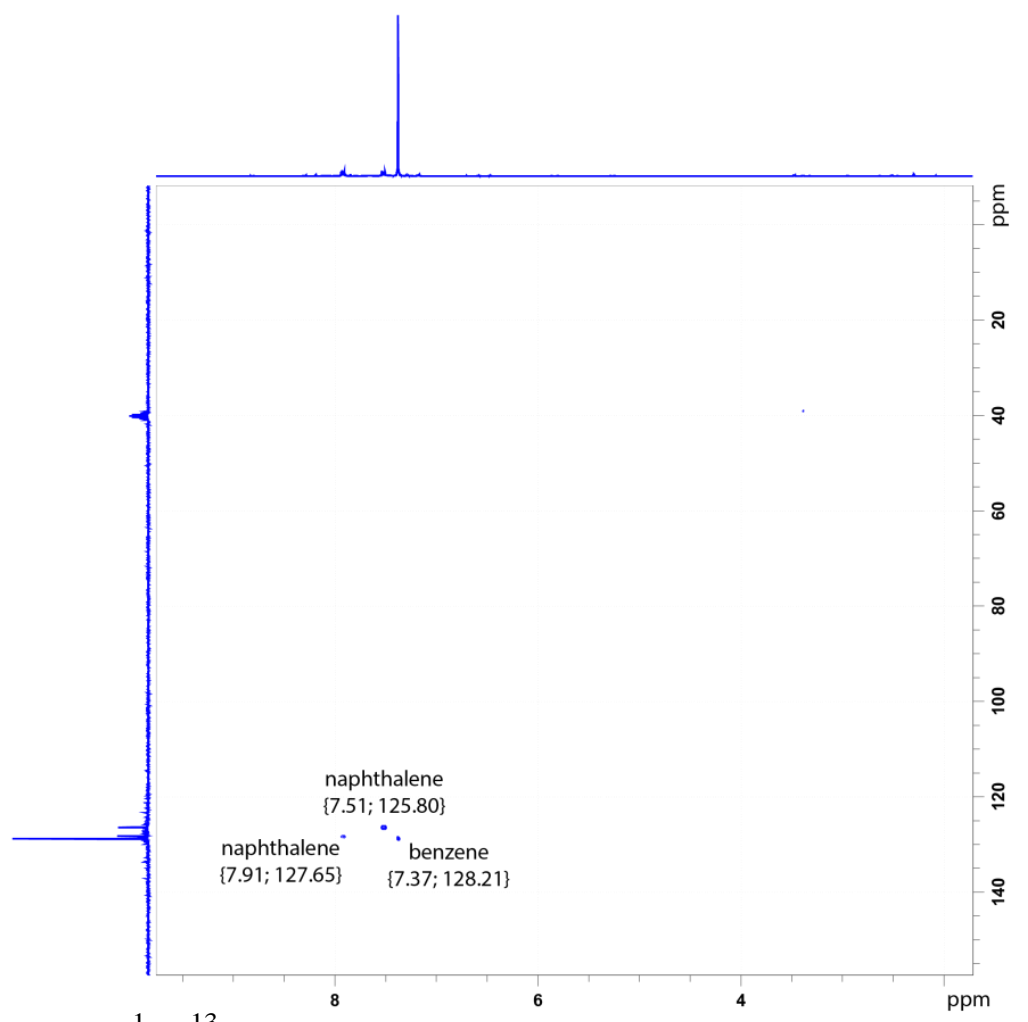

Figure S33. HSQC $\left({ }^{1} \mathrm{H}_{-}{ }^{13} \mathrm{C}\right)$ spectrum of the products after completion of the reaction. The signal at $128.21 \mathrm{ppm}$ in ${ }^{13} \mathrm{C}$ spectrum corresponds to the carbon atoms of benzene; the signals at $125.80 \mathrm{ppm}$ and $127.65 \mathrm{ppm}$ in ${ }^{13} \mathrm{C}$ spectrum correspond to the carbon atoms of naphthalene. 


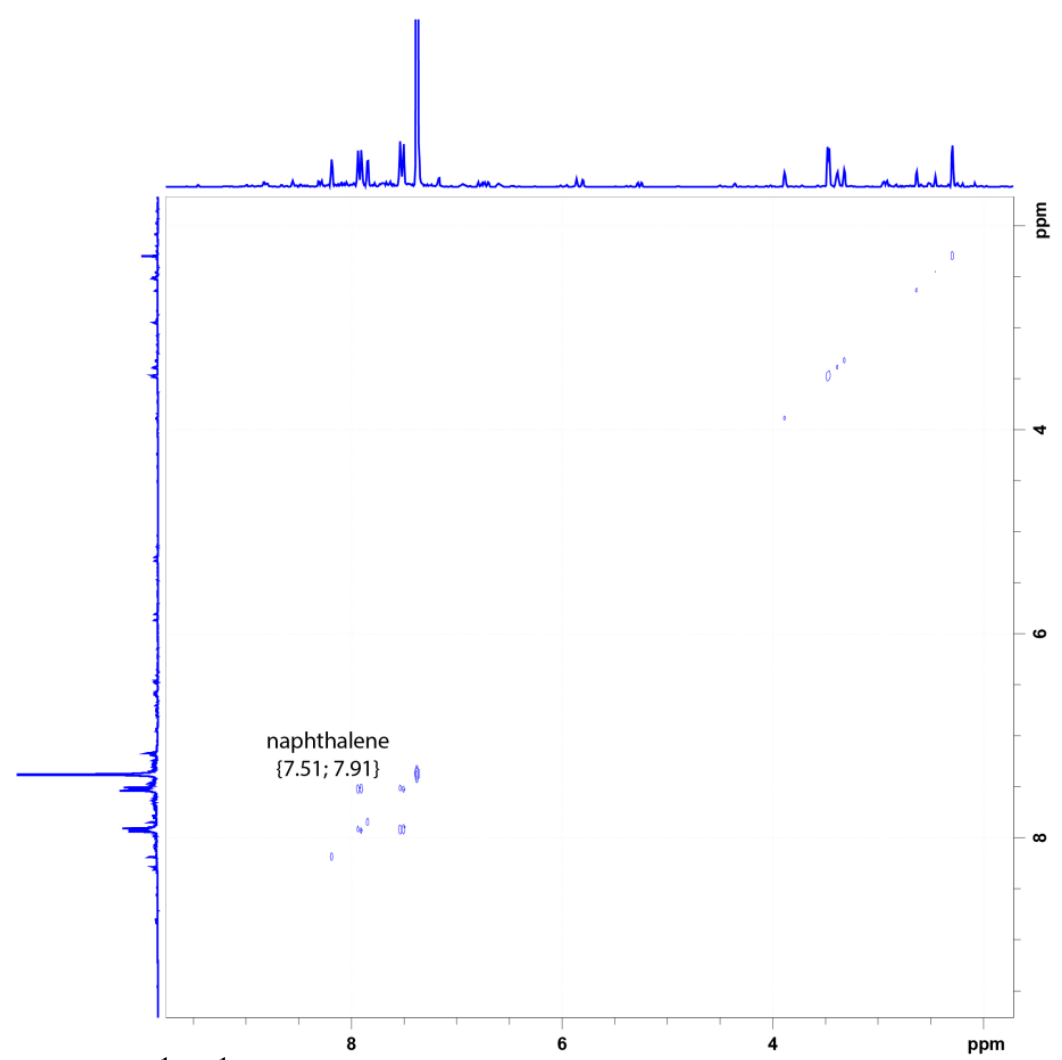

Figure S34. COSY $\left({ }^{1} \mathrm{H}^{1}{ }^{1} \mathrm{H}\right)$ spectrum of the products after completion of the reaction. The signals at $7.51 \mathrm{ppm}$ and $7.91 \mathrm{ppm}$ in ${ }^{1} \mathrm{H}$ spectrum correspond to the protons of naphthalene.

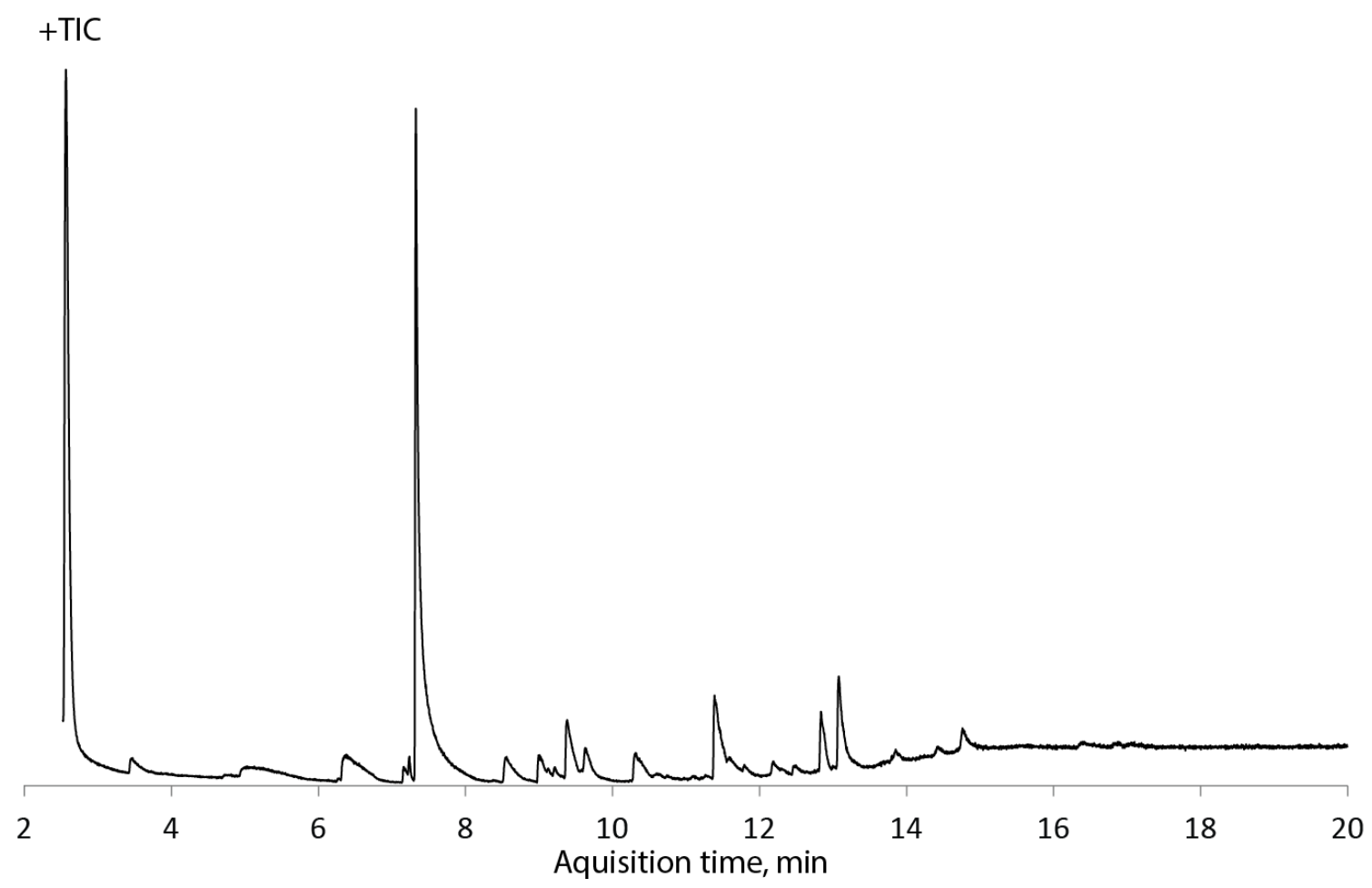

Figure S35. Gas chromatogram and mass spectrum of the reaction products after completion of the reaction. 


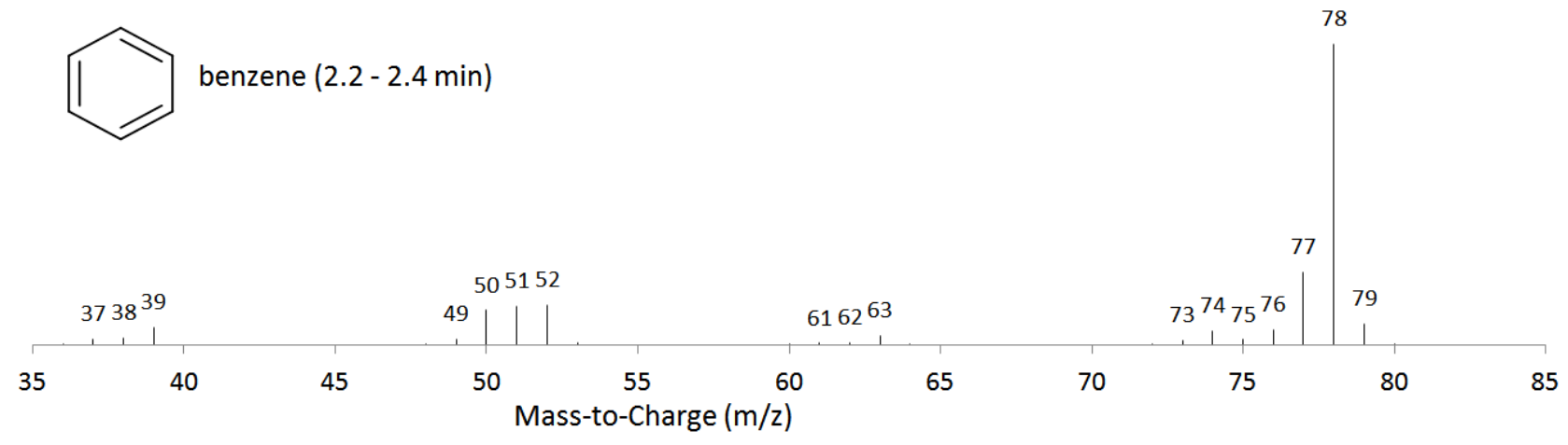

Figure S36. Mass spectrum of the fraction (retention time $2.2-2.4 \mathrm{~min}$ ) corresponding to benzene.

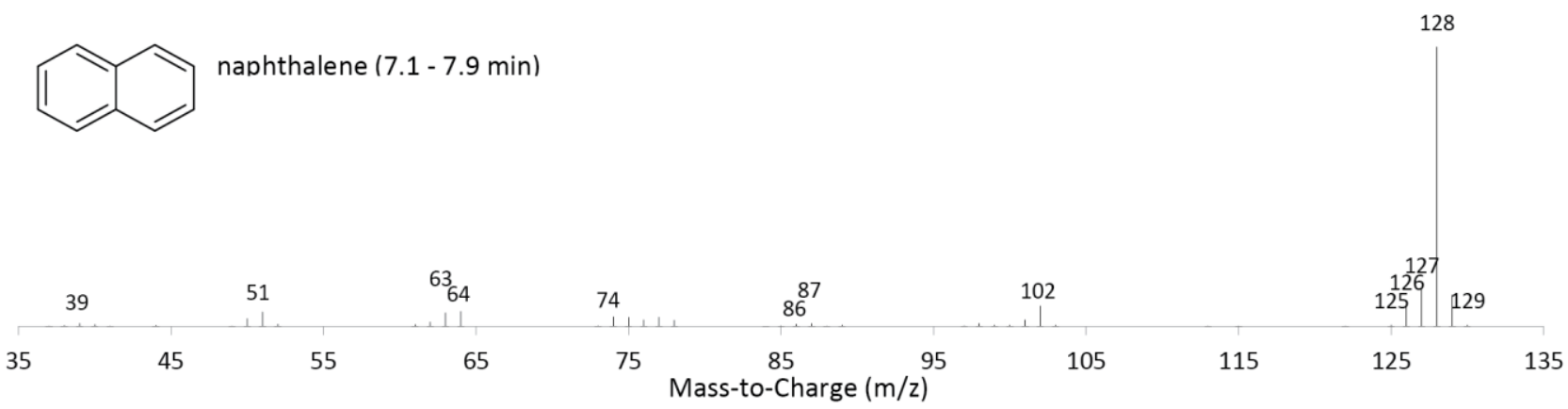

Figure S37. Mass spectrum of the fraction (retention time $7.1-7.9 \mathrm{~min}$ ) corresponding to naphthalene.

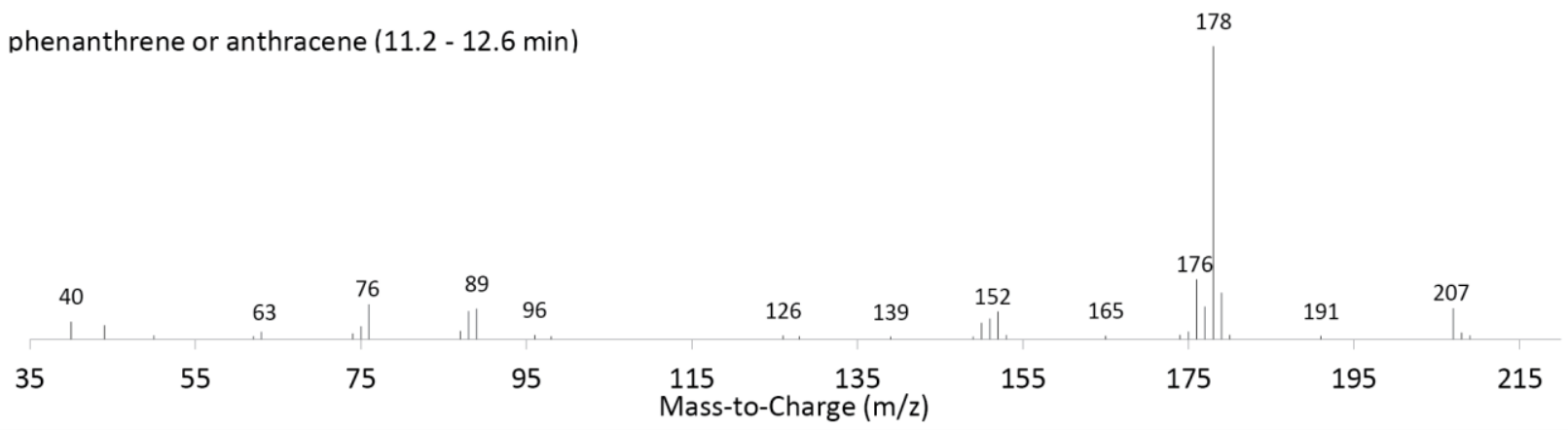

Figure S38. Mass spectrum of the fraction (retention time $11.2-12.6 \mathrm{~min}$ ) corresponding to anthracene or phenanthrene.

fluoranthene or pyrene $(12.7-12.8 \mathrm{~min})$

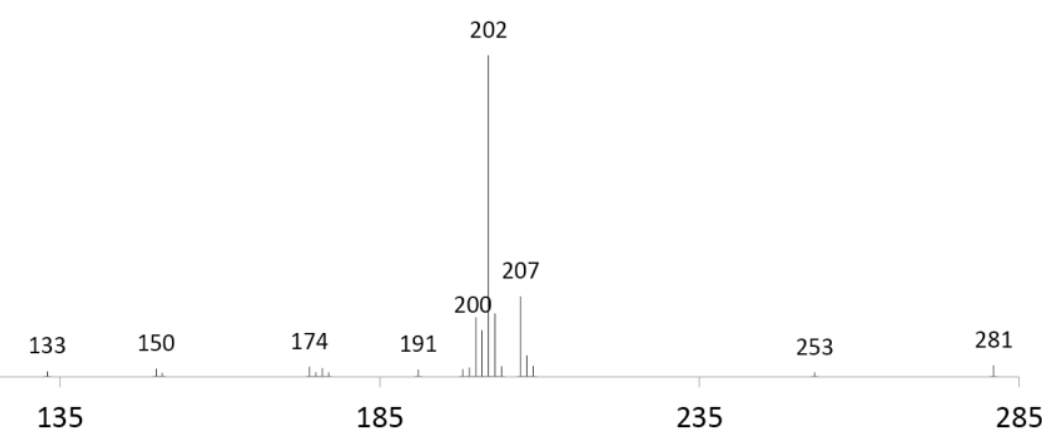

Figure S39. Mass spectrum of the fraction (retention time $12.7-12.8 \mathrm{~min}$ ) corresponding to fluoranthene or pyrene. 


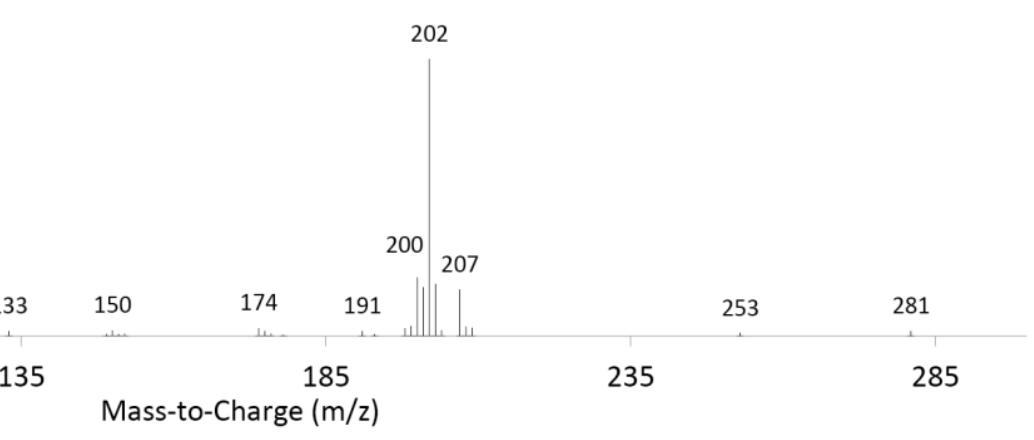

Figure S40. Mass spectrum of the fraction (retention time 12.9 - $13.3 \mathrm{~min}$ ) corresponding to pyrene or fluoranthene.

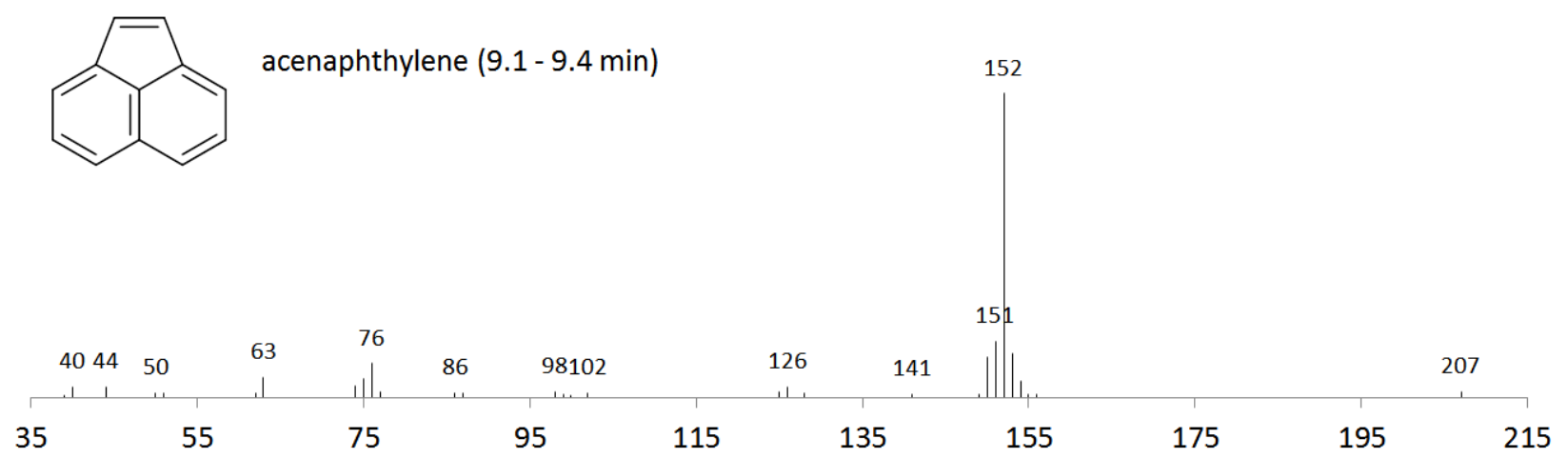

Figure S41. Mass spectrum of the fraction (retention time $9.1-9.4 \mathrm{~min}$ ) corresponding to acenaphthylene. 


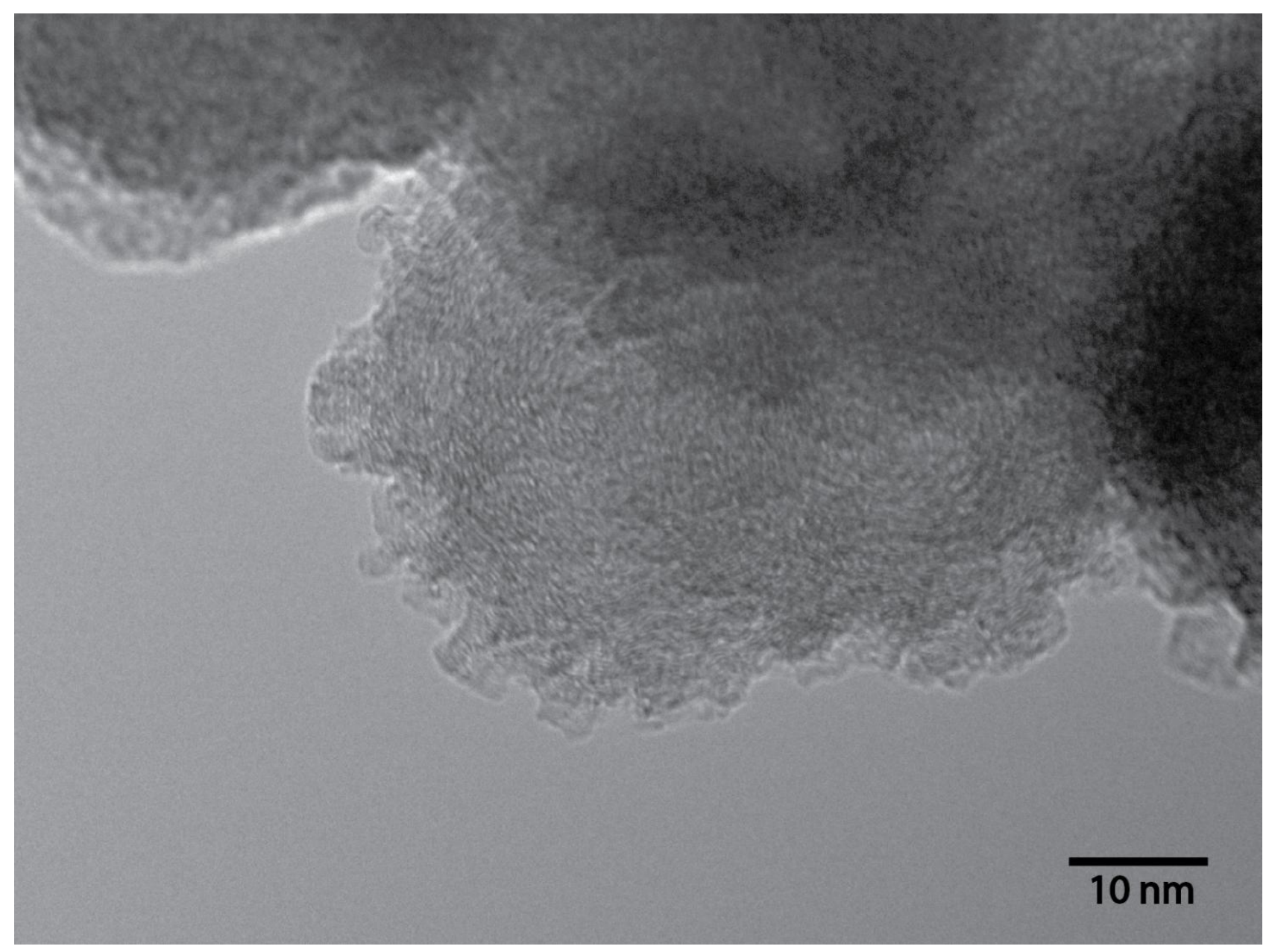

Figure S42. TEM image of a carbon flake formed on glass fiber surface during the reaction. 


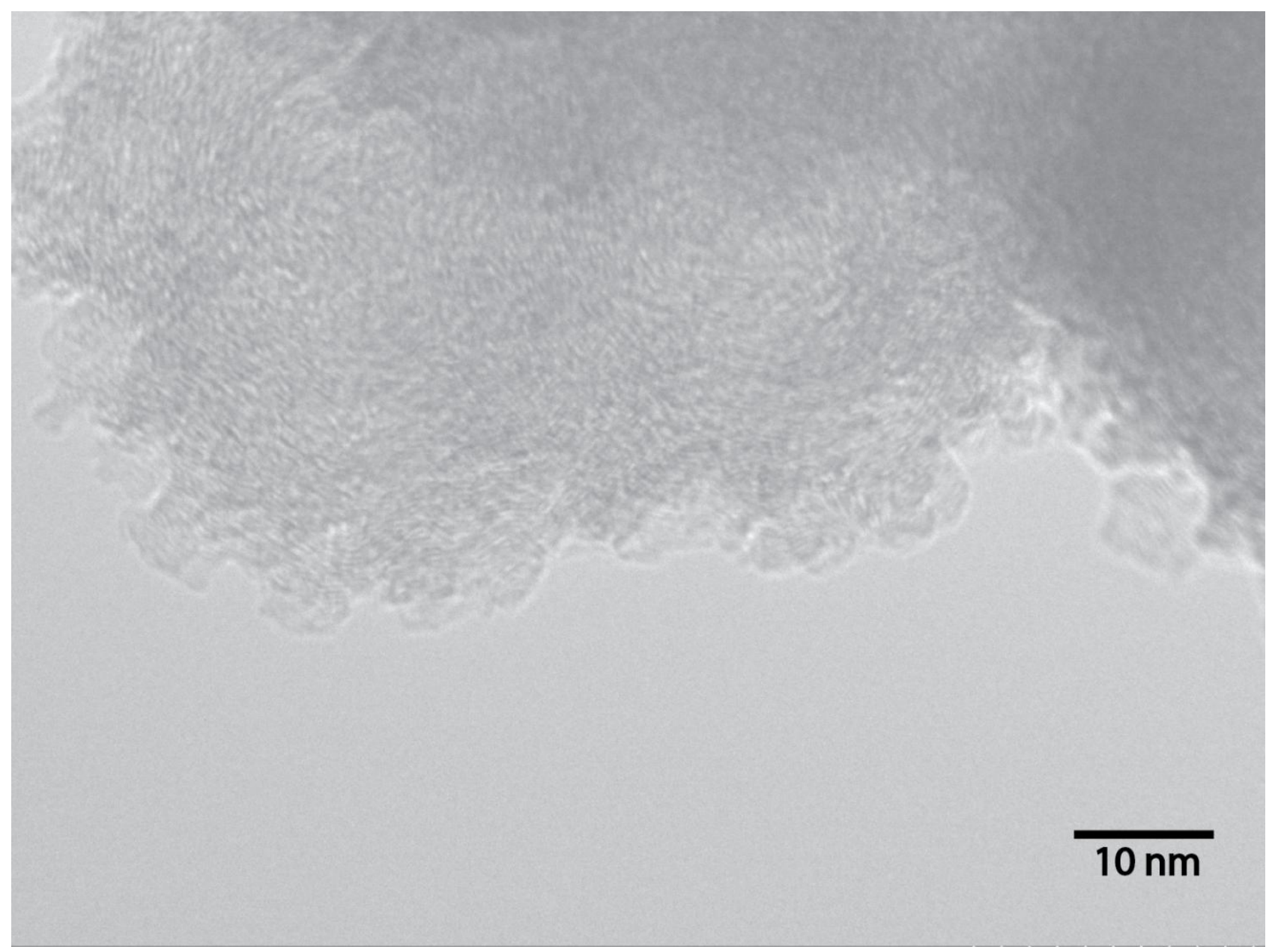

Figure S43. TEM image of a carbon flake formed on glass fiber surface during the reaction. 


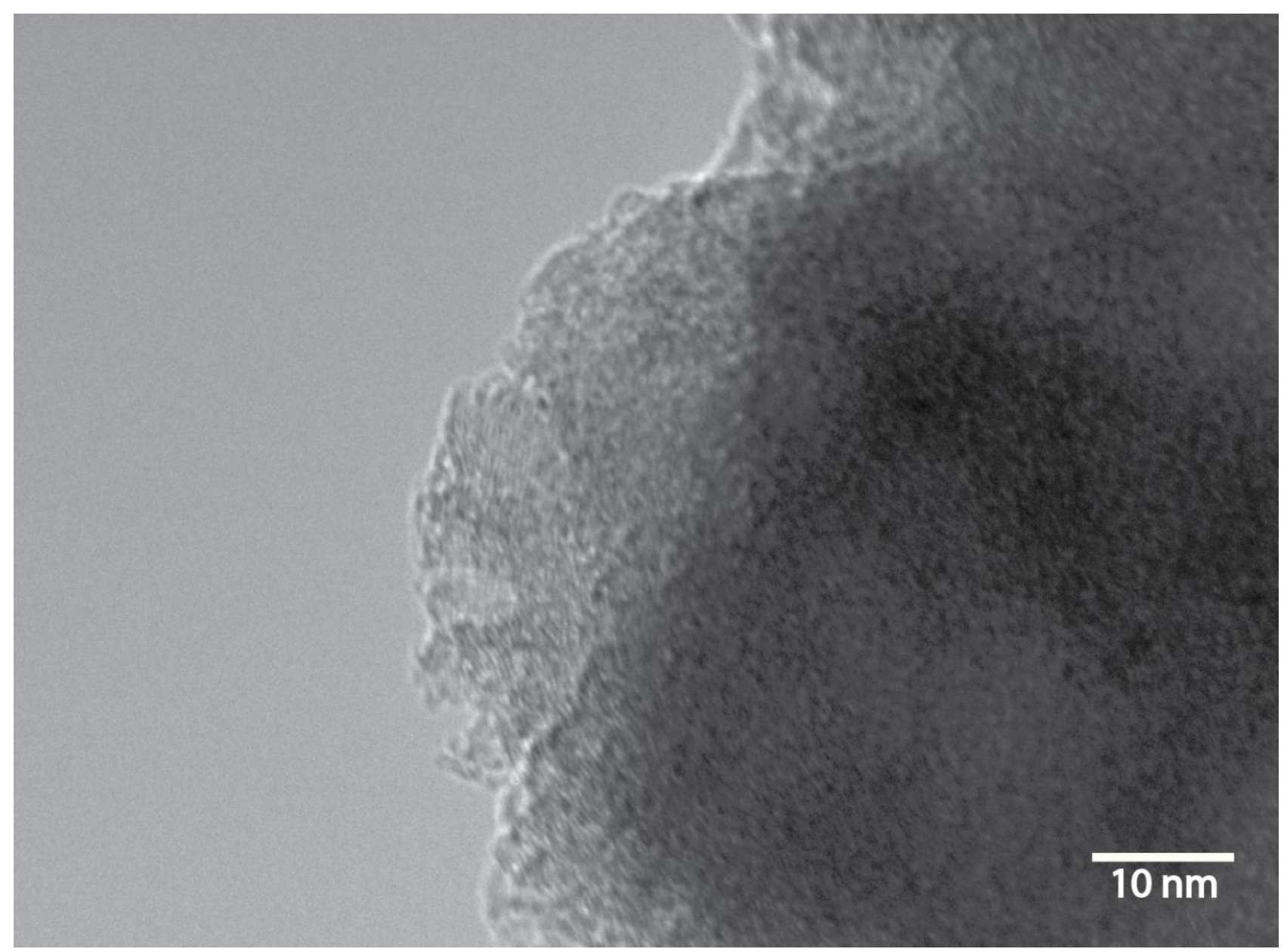

Figure S44. TEM image of a carbon flake formed on glass fiber surface during the reaction. 


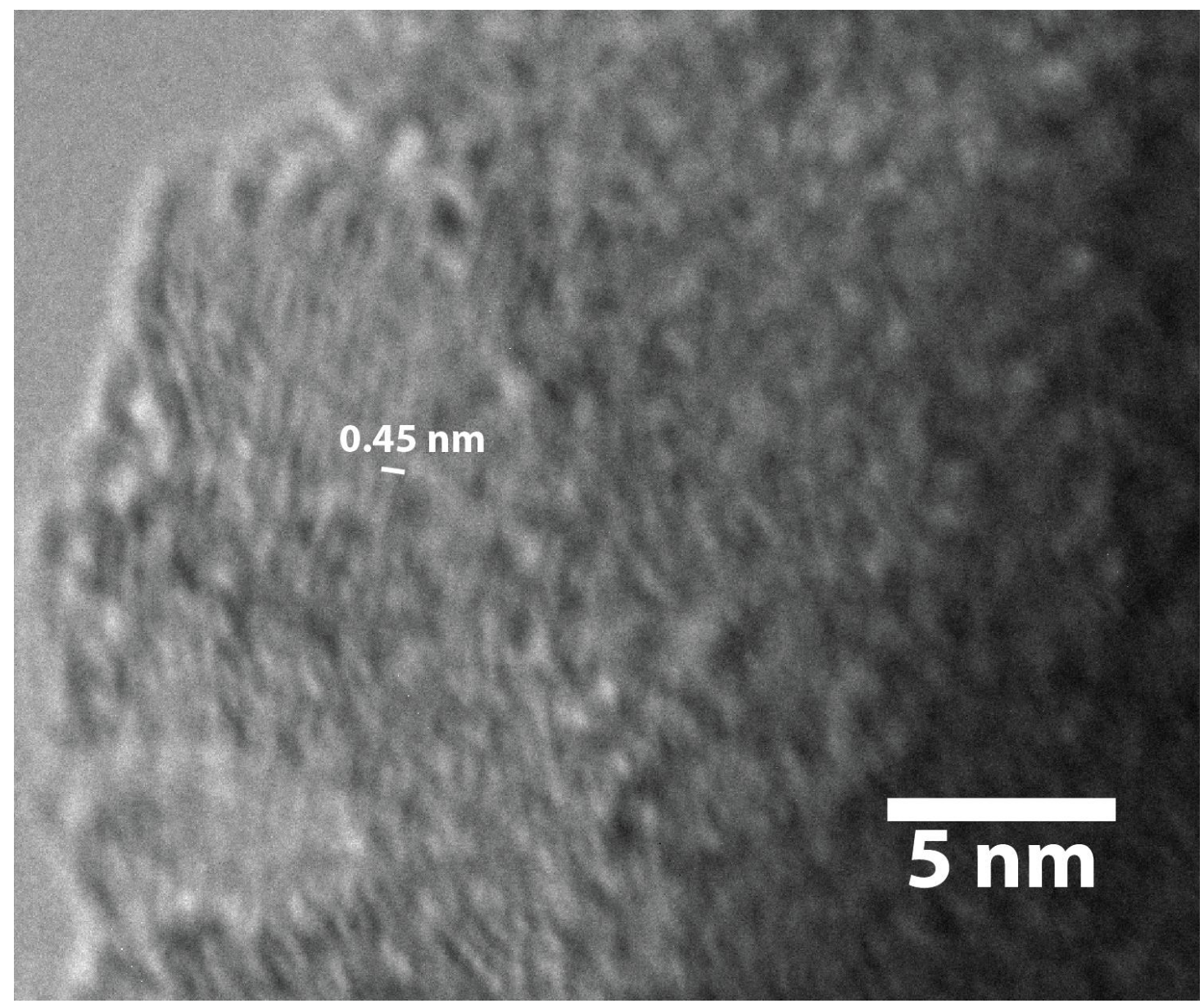

Figure S45. TEM image of a carbon flake formed on glass fiber surface during the reaction and an example of interlayer distance estimation. 


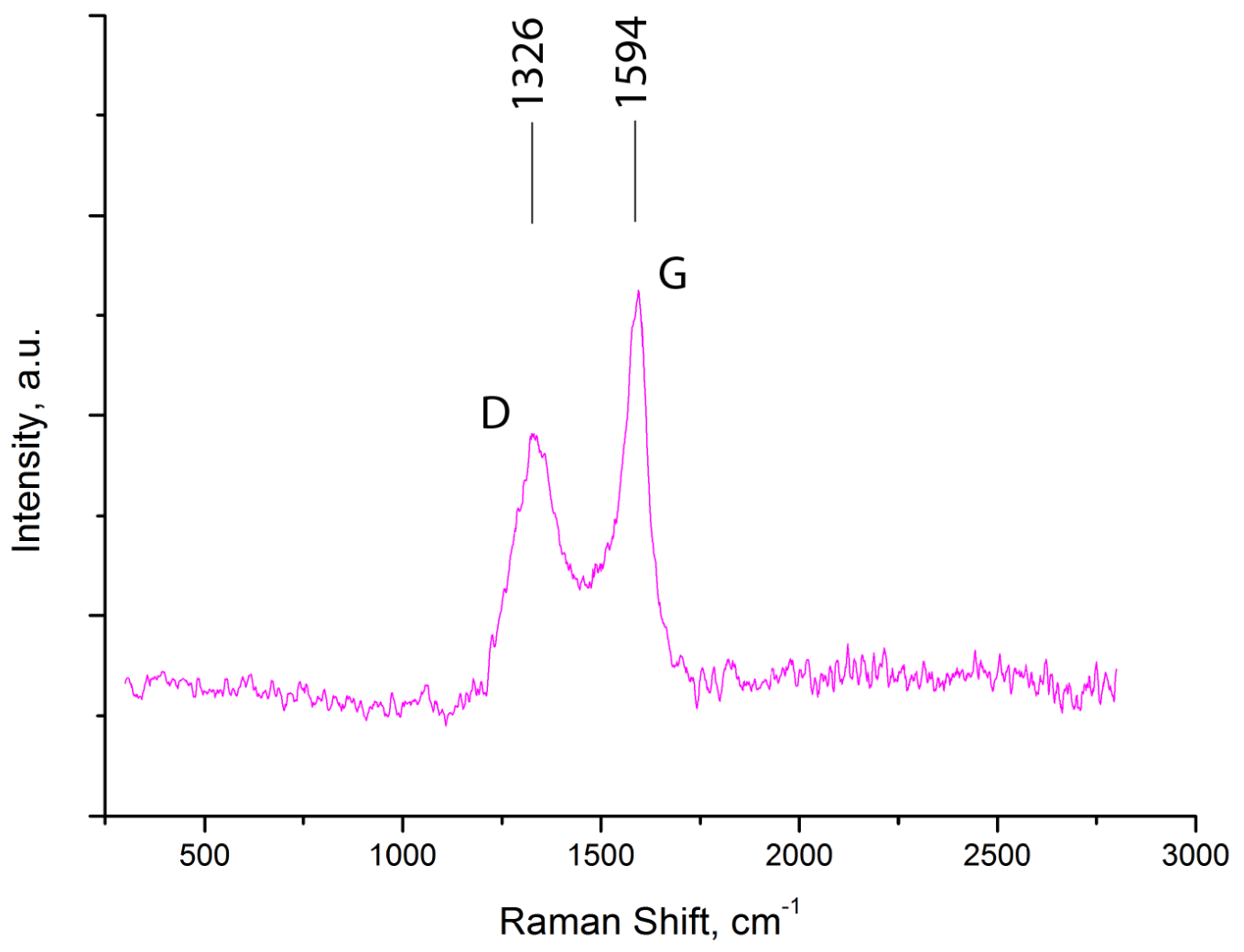

Figure S46. Raman spectrum of a carbon flake formed on glass fiber surface during the reaction; D and $\mathrm{G}$ modes at $1326 \mathrm{~cm}^{-1}$ and $1594 \mathrm{~cm}^{-1}$ are marked in the spectrum. 